Pacific Northwest

National Laboratory

Operated by Battelle for the

U.S. Department of Energy

\title{
Report on the North Anna Early Site Permit Water Budget Model (LakeWBT) for Lake Anna
}

\author{
C. B. Cook \\ L. W. Vail \\ D. L. Ward
}

January 2005

Prepared for the U.S. Department of Energy

under Contract DE-AC05-76RL01830 


\section{DISCLAIMER}

This report was prepared as an account of work sponsored by an agency of the United States Government. Neither the United States Government nor any agency thereof, nor Battelle Memorial Institute, nor any of their employees, makes any warranty, express or implied, or assumes any legal liability or responsibility for the accuracy, completeness, or usefulness of any information, apparatus, product, or process disclosed, or represents that its use would not infringe privately owned rights. Reference herein to any specific commercial product, process, or service by trade name, trademark, manufacturer, or otherwise does not necessarily constitute or imply its endorsement, recommendation, or favoring by the United States Government or any agency thereof, or Battelle Memorial Institute. The views and opinions of authors expressed herein do not necessarily state or reflect those of the United States Government or any agency thereof.

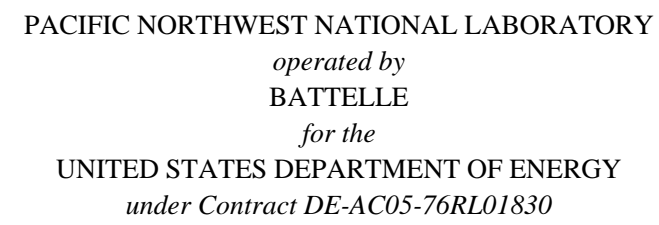

Printed in the United States of America

$$
\begin{aligned}
& \text { Available to DOE and DOE contractors from the } \\
& \text { Office of Scientific and Technical Information, } \\
& \text { P.O. Box 62, Oak Ridge, TN 37831-0062; } \\
& \text { ph: (865) 576-8401 } \\
& \text { fax: (865) 576-5728 } \\
& \text { email: reports@adonis.osti.gov }
\end{aligned}
$$

\footnotetext{
Available to the public from the National Technical Information Service, U.S. Department of Commerce, 5285 Port Royal Rd., Springfield, VA 22161 ph: (800) 553-6847 fax: (703) 605-6900

email: orders@ntis.fedworld.gov online ordering: http://www.ntis.gov/ordering.htm
} 


\title{
Report on the North Anna Early Site Permit Water Budget Model (LakeWBT) for Lake Anna
}

\author{
C. B. Cook \\ L. W. Vail \\ D. L. Ward
}

January 2005

Prepared for the Nuclear Regulatory Commission under Contract DE-AC05-76RL01830 


\section{Summary}

Operational activity of the North Anna Early Site Permit (ESP) plants was examined for detectable hydrological alterations to the environment, principally Lake Anna. Because ESP Unit 4 is proposed to use dry cooling towers, the only detectable hydrological alterations will result from the discharge of waste heat from ESP Unit 3. The additional discharge entering the discharge canal from Unit 3 will result in shorter times for water to travel in Lake Anna from the discharge location back to the unit's intake. Similarly, a decrease of lake volume due to additional forced evaporation from Unit 3 will also reduce travel time between the discharge location and the unit's intake.

Water budget modeling examined hydrological impacts from both the existing NAPS Units 1 and 2 and the once-through ESP Unit 3 operating continuously at a 100\% load factor. Four scenarios, including Unit 3 using an alternate cooling system (wet cooling towers), were selected to estimate and bound minimum water surface elevations (WSEs). A period of record of more than 23 years was examined to determine a critical historical period for comparison between the scenarios. The critical period selected was the 34 month period between June 2000 and April 2003, specifically targeting the minimum elevation occurring during early October (in the 2nd week) of 2002. Simulation results predict the following minimum WSEs for the critical period:

No units operating: $\quad 247.8 \mathrm{ft}$

Units 1 and 2 (existing/observed conditions): $\quad 245.1 \mathrm{ft}$

Units 1 and 2 plus Unit 3 using once through cooling: $\quad 243.5 \mathrm{ft}$

Units 1 and 2 plus Unit 3 using wet cooling tower cooling: $242.5 \mathrm{ft}$. 


\section{Contents}

$\begin{array}{lll}1.0 & \text { Background } & 1\end{array}$

1.1 Plant Parameter Envelope 2

1.2 Proposed ESP Facility 2

2.0 LakeWBT Model Development 5

2.1 LakeWBT Bathymetric Schematization 5

$\begin{array}{lll}2.2 & \text { LakeWBT Model Boundary Conditions } & 7\end{array}$

2.2.1 Inflows 8

2.2.2 North Anna Dam Releases 8

2.2.3 Meteorology 8

2.3 LakeWBT Water and Heat Budget Process Representation 9

$\begin{array}{ll}\text { 2.3.1 Evaporation Rate Formulations } & 10\end{array}$

2.3.2 Direct Scaled Water Temperature Approach 11

2.3.3 Constant Temperature Hot Thermal Pool Approach 11

2.3.4 Newton's Law of Cooling Approach 12

2.3.5 Approach Selection 13

3.0 LakeWBT Simulation Results

$\begin{array}{lll}4.0 & \text { Conclusions } & 19\end{array}$

References

Appendix A. Simulation Results for the Critical Period 39

Appendix B. Simulation Results for the Period of Observed Field Data 45 


\section{Figures}

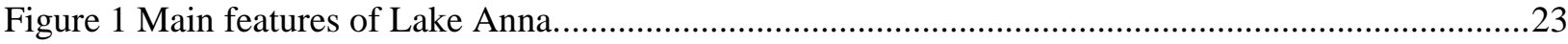

Figure 2 Main lake and main lake arm temperatures observed and computed by the MIT model. ............24

Figure 3 Date-averaged water temperatures for the WHTF, main lake, and equilibrium for the

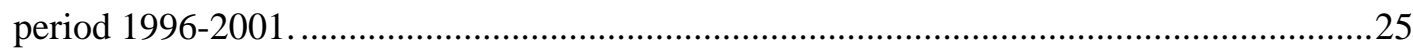

Figure 4 Long-term mean monthly precipitation and monthly precipitation during three driest water years in the record. .26

Figure 5 Five principle components used to compute heat flux at the water surface. Values shown are mean-daily values (Edinger, 1974)...

Figure 6 Water temperatures which provided the basis of the direct scaled temperature assessment.

Figure 7 Predicted and observed water surface elevations based on the direct scaled temperature approach

Figure 8 Water surface elevations predicted during the critical period using the constant temperature hot thermal pool approach

Figure 9 Relative fraction of lake volume as $95^{\circ} \mathrm{F}$ pool using the constant temperature hot thermal pool approach....

Figure 10 Inflows, outflows, precipitation and flow adjustments using Newton's Method: Units 1

\& 2 scenario.

Figure 11 Natural (ambient) evaporation rate for Lake Anna during the critical period...........................33

Figure 12 Natural and forced evaporation computed using Newton's Method: Units $1 \& 2$ scenario..........34

Figure 13 Monthly average evaporation rates in CFS and by main lake feature using Newton's

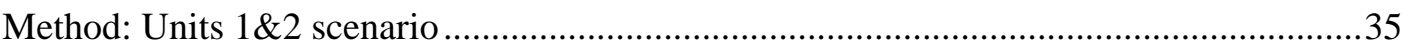

Figure 14 Volume fluxes for the critical period using Newton's Method: Units $1 \& 2$ scenario ...................36

Figure 15 Composite WSE predictions using Newton’s Law of Cooling Method.

\section{Tables}

Table 1 Computed areas and volumes as a function of water surface elevation for the various

zones of Lake Anna

Table 2 Monthly precipitation as a percentage of long-term monthly means during water years 2001 and 2002.

Table 3 Simulation average flux balance, in cfs, for the critical period (2000-2003).

Table 4 Simulation average flux balance, in cfs, for the period of record (1978-2003).....

Table 5 Water surface elevation exceedance tables for the 1978-2003 simulation period 


\subsection{Background}

On September 25, 2003, the U.S. Nuclear Regulatory Commission (NRC) received an application from Dominion Nuclear North Anna, LLC (Dominion) for an early site permit (ESP). The site proposed is located within the existing North Anna Power Station (NAPS) site near Mineral, Virginia. The September 25, 2003, Environmental Report (ER) of this application was revised by letters dated October 2, 2003 (Revision 1), July 15, 2004 (Revision 2), and September 7, 2004 (Revision 3). Any reference in this technical report to the ER refers to Revision 3 (Dominion 2004). Under NRC regulations in Title 10 of the Code of Federal Regulations (CFR) Part 52 and in accordance with the applicable provisions of 10 CFR Part 51, which are NRC regulations implementing the National Environmental Policy Act of 1969 (NEPA), the NRC is required to prepare an environmental impact statement (EIS) as part of its review of an early site permit (ESP) application. A separate safety evaluation report will also be prepared in accordance with 10 CFR Part 52.

An ESP is a Commission approval of a site or sites for one or more nuclear power facilities. The filing of an application for an ESP is a process that is separate from the filing of an application for a construction permit (CP) or a combined license (COL) for such a facility. The ESP application and review process makes it possible to evaluate and resolve safety and environmental issues related to siting before the applicant makes large commitments of resources. If the ESP is approved, the applicant can "bank" the site for up to 20 years for future reactor siting.

As part of its evaluation of the environmental aspects of the action proposed in an ESP application, the NRC prepares an EIS in accordance with 10 CFR 52.18. The EIS must address impacts of operation of reactors and associated facilities. In a review separate from the EIS process, the NRC analyzes the safety characteristics of the proposed site and emergency planning information.

Based on the NRC's review of the ESP application, public comments during scoping, comments from the Commonwealth of Virginia, and a letter from Hanover County, it was established that water supply and water temperature issues merited specific scrutiny by the NRC in their review of the application. Pacific Northwest National Laboratory staff developed a model, LakeWBT, to assist in bounding water surface elevation (WSE) fluctuations and water temperature impacts associated with the proposed ESP facility on Lake Anna and the North Anna River downstream from the lake. This report describes LakeWBT and its predictions when applied to bound the water budget and temperature impacts of a proposed facility at the North Anna site.

LakeWBT does not represent a state-of-the-science coupled process model. Field data, such as water velocities, required to calibrate such a model were not available at this site. Instead of providing highly detailed predictions, LakeWBT bounds the impacts. 
LakeWBT incorporates several bounding approaches. Several of the approaches were too conservative based on comparison with observations. Results from one of the bounding approaches are considered representative of the impacts.

\subsection{Plant Parameter Envelope}

As described in Subpart A of 10 CFR Part 52, the applicant for an ESP need not provide a detailed design of a reactor or reactors and the associated facilities but must provide sufficient bounding parameters and characteristics of the reactor or reactors and the associated facilities so that an assessment of site suitability can be made. Consequently, the ESP application may refer to a plant parameter envelope (PPE) as a surrogate for a nuclear power plant and its associated facilities.

A PPE is a set of values of plant design parameters that an ESP applicant expects bounds the design characteristics of the reactor or reactors that might be constructed at a given site. The PPE values are a surrogate for actual reactor design information. Analysis of environmental impacts based on a PPE approach permits an ESP applicant to defer the selection of a reactor design until the construction permit (CP) or combined license (COL) stage. The PPE reflects upper bounds of the values for each parameter that it encompasses rather than the characteristics of any specific reactor design.

\subsection{Proposed ESP Facility}

The PPE provides bounding constraints on portions of plant water use. Other constraints on plant water use are based on site-specific information. The two proposed ESP units involve considerably different cooling systems with vastly different water needs. The proposed ESP Unit 3 would utilize once-through cooling and the Waste Heat Treatment Facility (WHTF) in the same manner as the existing two NAPS units.

The proposed Unit 4 would utilize dry cooling towers. Whereas wet cooling towers rely primarily on the latent heat of vaporization of water to satisfy cooling demands, dry towers rely solely on the much smaller heat exchange between the air and the water in an enclosed radiator. The consumptive cooling water demands for dry cooling towers are negligible. Unit 4 will not be discussed further in this report.

The primary water demand for the proposed ESP Unit 3 is for condenser cooling. The proposed plant would be limited to withdraw 1,140,000 gpm through the intake structure. The once-through portion of the cooling system would return approximately the same amount of water to the discharge canal and the WHTF. The elevated temperature of the discharge would result in forced (induced) evaporative water losses, which are in addition to the natural (ambient) evaporative water losses from the lake. The natural evaporation is not included in the PPE and is a site-specific parameter. Only that volume of the water 
withdrawn from the lake through forced evaporative loss is considered a consumptive use.

During normal operation at full power, based on the PPE, the primary cooling system for each unit is required to reject $9.7 \mathrm{E}+09 \mathrm{BTU} / \mathrm{hr}$ to the environment. ESP Unit 3 will reject this heat load via a once through cooling system. This design is the same as for NAPS Units 1 and 2 in that Unit 3 will withdraw water from Lake Anna and discharge the heated effluent to the discharge canal. Based on the PPE the maximum temperature rise between the intake and the discharge will be $18^{\circ} \mathrm{F}$ and the maximum discharge temperature is $127^{\circ} \mathrm{F}$. The PPE states that the flow rate through the condenser will not exceed 1,140,000 gpm.

During low water conditions, the existing two NAPS units are allowed to operate down to elevation $244 \mathrm{ft}$. While the applicant is attempting to have the minimum pool elevation lowered to $242 \mathrm{ft}$, the analysis described herein assumes that minimum pool elevation is $244 \mathrm{ft}$. The applicant is proposing that ESP Unit 3 would also be allowed to operate down to $242 \mathrm{ft}$.

The normal cooling needs of Unit 3 will be provided by a once-through cooling design in conjunction with the WHTF. The once-through/WHTF cooling system relies primarily on evaporative heat transfer and long-wave heat transfer to the atmosphere to dissipate the rejected thermal load. This design results in less consumptive use of water than a conventional wet cooling tower for the same load. The PPE estimates a maximum forced evaporative loss of a once-through design to be 11,700 gpm (26 cfs) as compared to 19,500 gpm (43 cfs) for the wet cooling tower design. 


\subsection{LakeWBT Model Development}

Lake Anna is a hydrodynamically complex reservoir, whose circulation is impacted by numerous factors including: operation of the existing NAPS units, downstream water needs, lakeside housing with an associated desire for a constant WSE, variable upstream inflows, dynamic meteorological values, and operation of the Dike 3 weir. These features combine to produce zones within the lake containing large vertical and horizontal gradients of both water temperature and velocity.

Numerical simulation to examine impacts of ESP Unit 3 requires understanding of the major flow features contained within the lake, especially variations of water velocity at key locations. Unfortunately, this information is unavailable at present. Without adequate water velocity data, only an un-calibrated approximation of travel time from plant outfall to intake can be performed. Travel time information is critical, because the decay of water temperature from an elevated level to equilibrium temperature is not linear, but exponential. Therefore, the longer the water is exposed to the atmosphere the larger the loss of excess heat. In addition, small errors in travel time can compound to produce large errors in the estimation of heat flux at the water's surface.

Assuming adequate field data was available, a 3-D non-hydrostatic computational fluid dynamics (CFD) model should be applied to simulate the Dike 3 jet and near-field entrainment area. This zone is critical to understanding mixing in the main body of the lake, and will required detailed water velocity information as well as information regarding how Dike 3 will be operated once ESP Unit 3 is constructed. Outside of this zone, a 3-D hydrostatic CFD model could be applied to simulate the lateral and vertical temperature distribution within Lake Anna, including the WHTF. Because an adequate amount of field data was not available to perform a 3-D CFD modeling study, a simplified transient model was developed to estimate water surface elevations in the lake. This bounding model, LakeWBT, is described in the following sections.

\subsection{LakeWBT Bathymetric Schematization}

Digital 1:24,000 scale digital raster graphic (DRG) quadrangles of Lake Anna were downloaded from the Department of Geography at Radford University (http://www.runet.edu/ geoserve/Virginia.html). These images served as the source dataset for bathymetry to support LakeWBT. A mosaic of the raw images was used to generate a geo-referenced base map that was then digitized using the ESRI ${ }^{\mathrm{TM}}$ software package ArcMap TM 9.0. The resulting $10 \mathrm{ft}$ interval contours from elevation 180 to $250 \mathrm{ft}$ MSL are shown in Figure 1. 
A continuous surface was created from these contours, the surface of which was clipped at the source dataset elevation extremes. This surface was broken into three zones based upon observed water temperatures in the lake (see Figure 1): the WHTF, the main lake from North Anna dam upstream to the Highway 208 Bridge, and the lake arms upstream of the Highway 208 Bridge. Impounded surface areas and volumes were then calculated for each section as a function of water surface elevation, the results of which are presented in Table 1.

\begin{tabular}{|c|c|c|c|c|c|}
\hline \multicolumn{3}{|c|}{ Lake Anna } & \multicolumn{3}{|c|}{ WHTF } \\
\hline elevation (ft) & area (ac) & volume (ac-ft) & elevation (ft) & area (ac) & volume (ac-ft) \\
\hline 250 & 13,068 & 312,171 & 250 & 3,194 & 64,082 \\
\hline 240 & 9,219 & 200,737 & 240 & 2,120 & 37,515 \\
\hline 230 & 6,553 & 121,877 & 230 & 1,374 & 20,045 \\
\hline 220 & 4,418 & 67,021 & 220 & 830 & 9,026 \\
\hline 210 & 2,715 & 31,354 & 210 & 418 & 2,787 \\
\hline 200 & 1,281 & 11,377 & 200 & 139 & \\
\hline 190 & 523 & 3,257 & & & \\
\hline 180 & 129 & & & & \\
\hline \multicolumn{3}{|c|}{ Main Lake } & \multicolumn{3}{|c|}{ Lake Arms } \\
\hline elevation (ft) & area (ac) & volume (ac-ft) & elevation (ft) & area (ac) & volume (ac-ft) \\
\hline 250 & 5,540 & 174,374 & 250 & 4,334 & 73,715 \\
\hline 240 & 4,528 & 124,032 & 240 & 2,571 & 39,190 \\
\hline 230 & 3,614 & 83,323 & 230 & 1,565 & 18,509 \\
\hline 220 & 2,803 & 51,240 & 220 & 786 & 6,755 \\
\hline 210 & 2,034 & 27,055 & 210 & 263 & 1,512 \\
\hline 200 & 1,101 & 11,377 & 200 & 40 & \\
\hline 190 & 523 & 3,257 & & & \\
\hline 180 & 129 & & & & \\
\hline
\end{tabular}

Table 1 Computed areas and volumes as a function of water surface elevation for the various zones of Lake Anna (see Figure 1)

Lake Anna, a man-made reservoir formed when the North Anna Dam began to impound water, is comprised of numerous fingers and arms. The lake is approximately 17 miles long, and several dikes have been constructed to increase travel time from the discharge canal exit to the intake. Trapezoidal connecting canals have been constructed to convey flow from the three ponds formed by these dikes, and are labeled as ponds 1 through 3 in the figure. The collection of ponds and connecting canals are collectively labeled as the WHTF.

Water leaving the discharge canal may only exit the WHTF through Dike 3. This dike contains a submerged discharge structure with adjustable stop logs to baffle exiting discharge. This structure creates a positively buoyant high velocity (typically $>6 \mathrm{ft} / \mathrm{s}$ ) jet, that was designed to quickly entrain cooler main lake water.

The Massachusetts Institute of Technology (MIT) developed, calibrated, and validated a numerical model of Lake Anna. This model accurately produces results of the lake with the two existing reactors operating after undergoing a detailed calibration following construction of the existing reactors (MIT, 1984). Since the model hydrodynamic parameters are highly tuned to existing travel time conditions, especially through the 
WHTF, and since the decay of water temperature is exponential towards equilibrium, the model would need to be recalibrated once again to accurately predict water temperatures for conditions when the ESP reactor(s) are operating. This is not possible without the collection of field data obtained after the ESP reactor(s) have been constructed, and as was done previously after both units went online in 1980 .

Both observed and MIT model simulation results for existing reactor conditions show that year-to-year variations in daily averaged water temperatures are relatively small for both wet and dry watershed conditions. Water temperatures shown in Figure 2 span a sixyear period that includes years of relatively constant WSE and drought years when the WSE dropped approximately $5 \mathrm{ft}$ below normal pool elevation. Of note in this figure are the relatively small variations in water temperature throughout the main lake, and that these temperatures are several degrees above equilibrium temperature. Data collected in the arms upstream of the Highway 208 Bridge indicate that these zones are at equilibrium temperature, suggesting that little excess heat generated by the existing units is dissipated in these upstream regions.

Because the yearly cycle of water temperature is fairly consistent for the existing two reactor configuration, an approximation later used by LakeWBT is the yearly cycle of date-average water temperatures shown in Figure 3. This figure shows the gradual dissipation of heat through the system as water travels from the discharge canal, through the WHTF, and back towards the intake. Of note from these results are that Pond 2 discharge water temperatures are only slightly higher than Dike 3 (i.e. Pond 3 discharge) water temperatures. Also of note from these results are that the WHTF arm water temperatures are approximately equal to the temperature at Dike 3 . These results suggest that a large quantity of heat energy is being lost to the atmosphere between the discharge canal and Pond 2, although Dike 3 and main lake water temperatures are still significantly above equilibrium temperature.

\subsection{LakeWBT Model Boundary Conditions}

The model required input of time-series boundary condition data. Inflows to the lake are required for each time step, as are outflows which were computed using the North Anna Dam rating curve. Meteorological data was also required to compute evaporative fluxes. Lake inflows and meteorological data were held constant for all scenarios, however outflows varied between scenarios according to the water surface elevation of the lake.

The LakeWBT application to Lake Anna operated on a 6-hr time-step. This time-step size was selected because many lake processes occur on sub-daily intervals however, because these simulations spanned long historical periods (1978-2003), shorter time-steps were computationally prohibitive. Boundary condition data were linearly interpolated as needed for each time-step. 


\subsubsection{Inflows}

The principal tributaries of Lake Anna include the North Anna River, Pamunkey Creek, and Contrary Creek. Unfortunately, none of these tributaries contained stream flow gages during the 1996 through 2001 period when Lake Anna experienced a critical drought period. Because this critical drought period is the most severe on record, it was desirable to use this period and to develop synthetic inflows from an adjacent basin.

Daily average stream flows for Little River near Doswell, VA were obtained from US Geological Survey (http://waterdata.usgs.gov/nwis) gage 01671100. The size of the Little River watershed at this gaging station is $107 \mathrm{mi}^{2}$, which is approximately 3.2 times smaller than the North Anna watershed where it enters Lake Anna. Inflows to Lake Anna were therefore computed during the simulation period by multiplying the watershed scale ratio to the daily average Little River discharges.

\subsubsection{North Anna Dam Releases}

Outflows from the lake were based on the current operating rules for North Anna Dam. Releases are generally performed to maintain a water surface elevation of $250 \mathrm{ft}$. When the water surface elevation dropped below $250 \mathrm{ft}$ because of inadequate inflow to offset the natural and forced evaporative losses, releases from the dam were maintained at the normal minimum flow of $40 \mathrm{cfs}$. If the water surface elevation declined below $248 \mathrm{ft}$, releases were assumed to decrease to $20 \mathrm{cfs}$ immediately. In cases of severe declines in the lake water surface elevation, this assessment took into account the current lake level limit for Units 1 and 2 operation, $244 \mathrm{ft}$, and for the proposed Unit 3 limit, $242 \mathrm{ft}$. Once the water surface elevation rose above the intake threshold, the unit(s) was restarted.

\subsubsection{Meteorology}

Meteorological information about the atmosphere above the lake is necessary to compute evaporation in LakeWBT. Air temperature, dew point temperature, and wind speed were obtained from Richmond Airport (EarthInfo, 2003), which was the nearest location that collected data during the critical drought period. Hourly observed data were used as model inputs for the simulated drought period. Precipitation falling onto Lake Anna was considered an inflow boundary condition for the water budget model. Total accumulated precipitation on each day was obtained from National Climate Data Center (NCDC), and was originally collected at the Richmond Airport (NCDC, 2004).

Based on precipitation data measured at the Richmond, Virginia airport from January 1, 1921 to May 31, 2004, the second driest water year was 2002. Figure 4 shows the long term mean monthly precipitation, and monthly precipitation for three driest water years in the Richmond, Virginia record (water years 1924, 2002, and 1954). The total precipitation during the 2002 water year was 26.4 inches, 60.6 percent of mean annual precipitation. The 2001 water year was the twelfth driest year on record with a total 
precipitation of 33.1 inches, 75.9 percent of mean annual precipitation. Combined precipitation during water years 2001 and 2002 was the driest 2-year period in the precipitation record. Table 2 shows the monthly precipitation during water years 2001 and 2002 as a percentage of the long term corresponding monthly mean.

\begin{tabular}{|l|r|r|}
\hline \multirow{2}{*}{ Month } & \multicolumn{2}{|c|}{ Percentage of long-term monthly mean } \\
\cline { 2 - 3 } & Water Year 2001 & Water Year 2002 \\
\hline October & 0.3 & 20.4 \\
\hline November & 59.9 & 5.9 \\
\hline December & 76.8 & 53.9 \\
\hline January & 61.4 & 106.8 \\
\hline February & 73.9 & 23.8 \\
\hline March & 100.9 & 119.9 \\
\hline April & 68.9 & 75.1 \\
\hline May & 55.5 & 95.4 \\
\hline June & 176.2 & 42.1 \\
\hline July & 53.5 & 32.0 \\
\hline August & 106.4 & 66.6 \\
\hline September & 59.2 & 79.6 \\
\hline Total Annual & 75.9 & 60.6 \\
\hline
\end{tabular}

Table 2 Monthly precipitation as a percentage of long-term monthly means during water years 2001 and 2002.

\subsection{LakeWBT Water and Heat Budget Process Representation}

Analogous to a water budget, a generalized heat budget begins by considering the quantity of heat contained in a water body with a specified initial volume and temperature. Over time, heat will either enter or depart from the system through one of the volume's boundaries. Surface water inflows and outflows add or subtract heat to the system, as does groundwater although this flux is typically difficult to quantify.

Heat flux at the surface of the water body can be decomposed into the five components shown in Figure 5. A body of water is defined to be at equilibrium temperature when the flux of incoming and outgoing heat is equal; in other words, when the net heat flux is zero. Because the values of solar radiation, evaporation, etc. vary dramatically throughout the diurnal cycle, equilibrium temperature is generally calculated on a daily time step. Typical daily-average values of heat flux at mid-latitudes are shown in Figure 5 (Edinger, 1974). 


\subsubsection{Evaporation Rate Formulations}

Evaporation rate at the water's surface represents the volume per surface area per unit time of liquid water that is vaporized into the atmosphere. Numerous formulations to compute evaporation rate exist in the technical literature (see McCutcheon (1989), Edinger(1974), TVA(1972), Brutsaert(1991), Bras(1990)). Generally however, most formulations can be written in the following form:

$$
E=f(W)\left(e_{w s}-e_{a}\right)
$$

where $E$ is the evaporation rate $\left(\mathrm{m}^{3} / \mathrm{s} / \mathrm{m}^{2}\right.$ or $\left.\mathrm{m} / \mathrm{s}\right), \mathrm{e}_{\mathrm{a}}$ is the air-vapor pressure (mbar), $e_{w s}$ is the saturation vapor pressure of the air adjacent to the water surface (mbar), and $f(W)$ is a wind speed polynomial in the general form of:

$$
f(W)=a_{0}+a_{1} W+a_{2} W^{2} \ldots
$$

where $a_{0}, a_{1}$, and $a_{2}$ are constants $\left(\mathrm{mbar}^{-1}\right)$ and $\mathrm{W}$ is the speed of the wind at $2 \mathrm{~m}$ above the water surface $(\mathrm{m} / \mathrm{s})$.

Two separately recommended formulations from TVA (1972) and Edinger et al. (1974) were tested for sensitivity in the application of LakeWBT to Lake Anna. Simulation results produced almost identical monthly average evaporation rates with both formulations. The final formulation used to compute management scenarios for Lake Anna is the formulation recommended by TVA (1972), which is also reported in Bras(1990), and is credited to Marciano-Harbeck (1954). Formulations for both evaporation rate and vapor pressure calculations (Clausius-Clapeyron Equation) are as follows:

$$
\begin{gathered}
E=1.523 \times 10^{-9} W\left(e_{w s}-e_{a}\right) \\
e_{w s}=6.11 \exp \left[\frac{L_{\text {water }}}{R_{v}}\left(\frac{1}{273.15}-\frac{1}{\left(T_{\text {water }}+273.15\right)}\right)\right] \\
e_{a}=6.11 \exp \left[\frac{L_{\text {dew } p t}}{R_{v}}\left(\frac{1}{273.15}-\frac{1}{\left(T_{\text {dew } p t}+273.15\right)}\right)\right]
\end{gathered}
$$

where T represents water surface and dew point temperature in deg- $\mathrm{C}, R_{v}$ is the gas constant for water vapor $\left(461 \mathrm{~J} /\left({ }^{\circ} \mathrm{K} \mathrm{kg}\right)\right)$, and $L$ is the latent heat of vaporization $(\mathrm{J} / \mathrm{kg})$ of water. From Bras (1990), L was computed using the following equation, computed with either the water surface or dew point temperature, as appropriate:

$$
L=4186.8(597.3-0.57 \mathrm{~T})
$$

The evaporation rate equations are non-linear with respect to temperature, and relatively small variations in water surface and/or dew point temperatures can produce relatively large changes to the instantaneous evaporation rate. Additionally, any bias in the estimation of surface water temperature can accumulate over time to produce large errors between calculated and actual evaporation rates. 
Negative evaporation rates, also known as condensation, will occur whenever the water surface temperature falls below the atmospheric dew point temperature. Surplus water in the atmosphere reenters the liquid phase, thereby releasing the heat of condensation which is equal to the heat of vaporization. For this heat to be released to the lake, condensation must take place at the water's surface. In many cases, the presence of condensation nuclei in the air causes condensation to occur in the air above the water surface. When this occurs, the heat of condensation is released to the air under fog formation, not to the water surface. Therefore, heat input into the water surface by condensation cannot always be easily assessed. In LakeWBT, any negative evaporation rates were reset back zero and the heat gain by the water surface due to condensation was neglected.

\subsubsection{Direct Scaled Water Temperature Approach}

The first bounding approach attempted applied the most conservative approach. The PPE values for maximum rejected heat load and discharge were used to calculate the temperature rise in the lake. This method is conservative because it assumes that none of ESP Unit 3's waste heat exchanges heat with the atmosphere. Drawdown calculations compute evaporation (volume lost) based on these elevated temperatures, but evaporative cooling does not get fed back into the heat budget. Given the high recirculation rate between the intake and discharge (particularly during the critical period), the predicted impacts were very severe. Figure 6 shows the temperatures which provided the basis of the direct scaled temperature approach. The temperatures show a $14^{\circ} \mathrm{F}$ rise over observed (i.e. Units 1 and 2 operating, historical period values) water temperatures from the assumptions mentioned above. The results are overly conservative and resulted in the severe drawdown shown in Figure 7.

\subsubsection{Constant Temperature Hot Thermal Pool Approach}

The second approach attempted to be less conservative and more realistic than the direct scaled temperature approach and to be useful in both the lake temperature and water budget assessments. Clearly there is a tradeoff between conservatism in lake temperature and water budget calculations. Increasing evaporation reduces lake temperatures but also decreases the water level of the lake. Decreasing evaporation increases lake temperatures but also decreases water loss from the lake.

This approach incorporated another component of heat loss (long-wave back radiation) that is a significant source of heat loss in lakes (see Figure 5). The approach involved dividing the lake into two volumes. One volume was set at a user specified threshold temperature that was higher than the highest equilibrium temperature (natural lake temperature). This volume remained at the constant threshold temperature through the simulation; however, its volume as a fraction of the total lake volume would vary over time. The temperature of the second volume was the equilibrium temperature, which 
varied over time. Both of the volumes evaporated water according to their respective temperatures. Both volumes also lost heat according to Boltzman's Equation for black body radiation. Generally, due to buoyancy of the warmer water, the surface area of the warmer would be larger making this a conservative assumption relative to heat loss. Heat fluxes (evaporative cooling, black body radiation, reject heat from the units) resulted in exchanges in water between the two volumes to maintain the appropriate temperatures in the volumes while preserving the total energy content.

Example results for the constant temperature hot thermal pool approach are shown in Figure 8 and Figure 9. Figure 8 shows computed time-series of water surface elevation for all scenarios with a threshold temperature of $95^{\circ} \mathrm{F}$. Consistent with expectations, the cooling tower scenario results in a larger water surface elevation drawdown than the once-through cooling design. Figure 9 shows the relative fraction of the lake volume as an equivalent $95^{\circ} \mathrm{F}$ pool for the various scenarios. This outcome is consistent with expectations, with the relative lake volume fraction being largest for the ESP Unit 3 once-through tower design however, the fraction of the lake experiencing the $95^{\circ} \mathrm{F}$ threshold temperature is higher than observations would suggest.

\subsubsection{Newton's Law of Cooling Approach}

The third bounding approach was based on Newton's Law of Cooling, which defines an exponential decay in temperature between a body of a limited thermal mass in contact with another body of infinite thermal mass and constant temperature. This approach involved several steps. First the natural background and forced evaporation from Units 1 and 2 were computed by assigning non-uniform surface water temperatures using the calibrated MIT model results (see Figure 2 and Figure 3). To assign the water temperatures, the lake was decomposed into four zones (see Figure 1): WHTF arms, main WHTF, main lake, lake arms. The main WHTF zone was conservatively assigned the plant discharge temperature. The WHTF arms and main lake temperatures were conservatively assigned to equal Dike 3 and Burrus Point temperatures, respectively; however an exponential decay (Newton's Law of Cooling) was applied to the MIT computed results. The decay coefficient was based on the lake volume at the previous time step and was applied to account for any velocity changes that might occur as the lake volume varied through the simulation. The main lake arms were assigned to equal the equilibrium temperature, and therefore evaporated water at the natural background rate.

Next the volumetric water balance was computed using the appropriate watershed inflows, precipitation, dew point temperature, wind speed, and North Anna Dam outflows which were based on the previous time step water surface elevation. The resulting volume was converted to a water surface elevation, and compared to observed data. Any differences in water surface elevation were accounted for by allowing an inflow adjustment that could be either negative or positive to force computed water surface 
elevations to match observed. The inflow adjustment was usually small compared to lake inflows and outflows, and averaged -6.7 cfs (net withdrawal) over the 1978-2003 simulation period (see Table 3 and Table 4).

Once the natural and Unit 1 and 2 forced evaporation values were computed, the model applied constant evaporation rates for Unit 3, when appropriate, based on PPE values. PPE estimates for once-through forced evaporation would be difficult to validate and monitor in the field, however the evaporative loss for a wet cooling tower is bounding. WSE values were calculated for both once-through and wet tower designs. In these calculations changes in surface area and volume as a result of drawdown were explicitly considered. In addition, a fourth scenario was considered where forced evaporation was zero, and the entire lake surface was at equilibrium temperature, thereby evaporating at the natural evaporation rate. This scenario is called the "no units" case.

\subsubsection{Approach Selection}

The final approach selected for the analysis of water surface elevations in Lake Anna was the Newton's Law of Cooling approach. Although the direct scaled water approach is bounding, values were not realistic. The Newton's Law of Cooling approach provided water surface elevations that were conservative, and allowed for evaluation of various cooling tower alternatives by examining relative differences during a critical period. 


\subsection{LakeWBT Simulation Results}

While the entire period of October 15, 1978 through April 9, 2003 was simulated, the critical water surface elevation period was between June 1, 2000 and April 9, 2003. During the critical period the region experienced a severe drought, and concern over water use conflicts rose as the WSE in Lake Anna dropped to record lows in October 2002.

The inflow and outflow water balance terms for Lake Anna during the critical period with Units 1 and 2 operating are shown in Figure 10. The average inflow to the lake during the critical period was 163.2 cfs while outflows, following the North Anna Dam rating curve, averaged 127.7 cfs. Average precipitation falling on the lake, which is a function of lake surface area, averaged 55.7 cfs.

Both forced and natural evaporation was computed by the model at each time step and for each zone (i.e. WHTF arms, WHTF, main lake, and main lake arms). Natural evaporation rates were computed based upon equilibrium water temperatures and meteorological conditions, and rates varied throughout the simulation (see Figure 11). The average natural evaporation rate for the entire period averaged $42.7 \mathrm{in} /$ year and during the critical simulation period averaged 38.8 in/year, both of which closely match values reported in Van der Leeden et. al. (1990). Forced evaporation induced by Units 1 and 2 was computed based upon the surface water temperature for each lake zone (see Figure 3) and meteorological conditions, and also varied throughout the simulation.

Average natural and forced evaporation flow rates computed by the model during the critical simulation period when Units 1 and 2 were operating were $55.6 \mathrm{cfs}$ and $47.2 \mathrm{cfs}$, respectively, and time-series values are shown in Figure 12. Monthly evaporation rates for each zone of the lake are shown in Figure 13, and it should be noted that values shown as "WHTF" are the sum of evaporation rates computed for both the WHTF arms and main portion of the WHTF. By summing these two WHTF components, it is easier to compare where evaporation occurs in the lake; over $40 \%$ occurs in the WHTF, although the WHTF comprises only $24 \%$ of the surface area of the lake. The main lake surface area is only slightly larger than the lake arms (42\% versus $33 \%$ ), however $41 \%$ of the evaporation occurs in the main lake and less than $20 \%$ occurs in the lake arms.

An inflow adjustment added or subtracted water from the lake to force model computed WSEs to match observed WSEs at the end of each time step during the simulations. The adjustment was generally small and during the critical period averaged $+11.9 \mathrm{cfs}$ or, stated another way, approximately $7 \%$ of the average inflow (see Figure 10 ). While the average correction was positive and added water to the lake, during the minimum water surface elevation period (summer and fall of 2002) the inflow correction was negative and was reducing the amount of water in the lake. The average inflow correction for the entire simulation period (1978-2003) was -6.7 cfs (net loss), as shown in Table 4. 
Once the inflow and outflow terms were computed for each 6-hr time step, the water balance and corresponding WSE was computed. Monthly averages for each of the terms in the water budget are shown in the upper portion of Figure 14 for the Units 1 and 2 operating scenario. During the summer and fall of 2001 and 2002, the lack of inflow and precipitation can be seen. Dam outflows during much of 2002 were at either 40 or 20 cfs. The relative size of natural versus forced evaporation throughout the yearly cycle can also be seen. The bottom portion of Figure 14 displays the net sum of all terms in the water balance; negative implying losses from the lake. During the 21 month critical drought period between January 2001 and September 2002, only 33\% were positive and several of these were only slightly positive. From this figure, one can see that the minimum WSEs that occurred during October 2002 were precipitated by numerous negative or net loss months, the most significant of which occurred between March 2001 and November 2001.

LakeWBT produced results for the other scenarios that are similar to those presented above for the Units 1 and 2 scenario. These results are summarized in Table 3 for the critical simulation period between June 2000 and April 2003, and Table 4 displays an equivalent summary for the October 1978 through April 2003 period of record simulations. For each term, negative values have been assigned to flows leaving the lake. During the simulation, precipitation and evaporation vary due to the lake's surface area and therefore also vary between scenarios because WSEs are not equal. The inflow adjustment and watershed inflow are not varied between scenarios because they are not dependent upon the size of Lake Anna and were calibrated using observed data. The net result of summing all terms for any one scenario approximately equals zero.

For all simulations, whenever the WSE dropped below elevation $244 \mathrm{ft}$, Units 1 and 2 were shut off. The simulation average forced evaporation for simulations with Unit 3 are therefore less than the sum of forced evaporation for Units 1 \& 2 plus the PPE values for Unit 3. For the critical period scenarios, the Unit 3 once-thru case is different by approximately $4.1 \mathrm{cfs}(47.2+26.1-69.2)$, while the Unit 3 towers case is different by approximately $7.6 \mathrm{cfs}(47.2+43.5-83.1)$. Because Units 1 and 2 only shut off during part of 2002, the simulation averaged forced evaporation for the longer scenarios are much closer to the sum of the forced evaporation; Unit 3 once-thru is 0.5 cfs $(50.2+26.1$ - 75.8) and Unit 3 tower is 0.9 cfs $(50.2+43.5-92.8)$.

\begin{tabular}{lrrrrrr}
\multicolumn{1}{c}{} & \multicolumn{2}{c}{$\begin{array}{c}\text { Precip falling } \\
\text { Inflow }\end{array}$} & $\begin{array}{r}\text { Natural } \\
\text { On the lake }\end{array}$ & $\begin{array}{r}\text { Forced } \\
\text { Evaporation }\end{array}$ & $\begin{array}{r}\text { Inflow } \\
\text { Evaporation }\end{array}$ & $\begin{array}{l}\text { Adjustment } \\
\text { No Units }\end{array}$ \\
\cline { 2 - 7 } & 163.2 & -174.7 & 57.4 & -57.3 & 0.0 & 11.9 \\
Units 1\&2 & 163.2 & -127.7 & 55.7 & -55.6 & -47.2 & 11.9 \\
Units 1\&2 + 3OnceThru & 163.2 & -105.7 & 54.4 & -54.2 & -69.2 & 11.9 \\
Units 1\&2 + 3Tower & 163.2 & -92.0 & 53.5 & -53.3 & -83.1 & 11.9
\end{tabular}

Table 3 Simulation average flux balance, in cfs, for the critical period (2000-2003). 


\begin{tabular}{lrrrrrr}
\multicolumn{1}{c}{} & \multicolumn{2}{c}{$\begin{array}{c}\text { Precip falling } \\
\text { Inflow }\end{array}$} & $\begin{array}{r}\text { Outflow } \\
\text { on the lake }\end{array}$ & $\begin{array}{r}\text { Natural } \\
\text { Evaporation }\end{array}$ & $\begin{array}{r}\text { Forced } \\
\text { Evaporation }\end{array}$ & $\begin{array}{r}\text { Inflow } \\
\text { Adjustment }\end{array}$ \\
\cline { 2 - 7 } No Units & 296.0 & -290.2 & 65.4 & -64.1 & 0.0 & -6.7 \\
Units 1\&2 & 296.0 & -240.0 & 64.7 & -63.4 & -50.2 & -6.7 \\
Units 1\&2 + 3OnceThru & 296.0 & -214.4 & 64.1 & -62.9 & -75.8 & -6.7 \\
Units 1\&2 + 3Tower & 296.0 & -197.4 & 63.6 & -62.3 & -92.8 & -6.7
\end{tabular}

Table 4 Simulation average flux balance, in cfs, for the period of record (1978-2003).

Variations in WSEs over the critical period for all scenarios are shown in Figure 15. The lake begins each simulation at normal pool elevation (250 ft) and rises and falls over the simulation. Storm events near May 2001 result in a return to full pool before the onset of the drought period. All simulations were extended in time until the computed WSE in Lake Anna returned to normal pool.

Table 5 presents the number of days any particular scenario was at or below key lake thresholds during the 8943 days simulated between October 1978 and April 2003. Percent increase (negative implies decrease) are also provided relative to the "No Units" operating scenario and the currently existing "Units $1 \& 2$ ”. The percent of time of the simulation is also provided as a reference.

Several items are of note in the table. First, even without any units operating, the lake WSE would be below elevation $250 \mathrm{ft}$ approximately $45 \%$ of the time. In the most extreme case with all three units operating, the lake is below elevation $250 \mathrm{ft}$ more than $70 \%$ of the time. A second noteworthy item is that the lake would be below elevation 244 ft only $1 \%$ of the time if Unit 3 were constructed. The relative increase in the amount of time the lake is below elevation 248 is quite dramatic, however, if Unit 3 is constructed. 
At or Above 250

\begin{tabular}{lrrrr} 
Scenario & $\begin{array}{r}\text { Number } \\
\text { of Days }\end{array}$ & $\begin{array}{r}\text { Percent Increase } \\
\text { Relative to No Units }\end{array}$ & $\begin{array}{r}\text { Percent Increase } \\
\text { Relative to Units 1\&2 }\end{array}$ & $\begin{array}{r}\text { Percent } \\
\text { of Simulation }\end{array}$ \\
\cline { 2 - 5 } No Units & 4948 & & & $55 \%$ \\
Units 1\&2 & 3069 & $-38 \%$ & $-20 \%$ & $34 \%$ \\
Units 1\&2+3OT & 2445 & $-51 \%$ & $-27 \%$ & $27 \%$ \\
Units 1\&2+3Tower & 2230 & $-55 \%$ & $25 \%$
\end{tabular}

Below 250

\begin{tabular}{lrrrr}
\multicolumn{1}{l}{ Scenario } & $\begin{array}{r}\text { Number } \\
\text { of Days }\end{array}$ & $\begin{array}{r}\text { Percent Increase } \\
\text { Relative to No Units }\end{array}$ & $\begin{array}{r}\text { Percent Increase } \\
\text { Relative to Units 1\&2 }\end{array}$ & $\begin{array}{r}\text { Percent } \\
\text { of Simulation }\end{array}$ \\
\cline { 2 - 5 } No Units & 3995 & & & $45 \%$ \\
Units 1\&2 & 5874 & $47 \%$ & $11 \%$ & $66 \%$ \\
Units 1\&2 +3OT & 6498 & $63 \%$ & $14 \%$ & $73 \%$ \\
Units 1\&2 +3Tower & 6713 & $68 \%$ & $75 \%$
\end{tabular}

Below 248

\begin{tabular}{lrrrr} 
Scenario & $\begin{array}{r}\text { Percent Increase } \\
\text { of Days }\end{array}$ & $\begin{array}{r}\text { Percent } \\
\text { Relative to No Units }\end{array}$ & $\begin{array}{r}\text { Pelative to Units 1\&2 } \\
\text { Re Simulation }\end{array}$ \\
\cline { 2 - 5 } No Units & 32 & & & $0 \%$ \\
Units 1\&2 & 481 & $1403 \%$ & $121 \%$ & $5 \%$ \\
Units 1\&2+3OT & 1065 & $3228 \%$ & $233 \%$ & $12 \%$ \\
Units 1\&2 +3Tower & 1604 & $4913 \%$ & $18 \%$
\end{tabular}

\section{Below 244}

\begin{tabular}{lrrrr} 
Scenario & $\begin{array}{r}\text { Number } \\
\text { of Days }\end{array}$ & $\begin{array}{r}\text { Percent Increase } \\
\text { Relative to No Units }\end{array}$ & $\begin{array}{r}\text { Percent Increase } \\
\text { Relative to Units 1\&2 }\end{array}$ & $\begin{array}{r}\text { Percent } \\
\text { of Simulation }\end{array}$ \\
\cline { 2 - 5 } No Units & 0 & & & $0 \%$ \\
Units 1\&2 & 0 & $0 \%$ & N/A & $0 \%$ \\
Units 1\&2+3OT & 71 & N/A & N/A & $1 \%$ \\
Units 1\&2 +3Tower & 129 & N/A &
\end{tabular}

Table 5 Water surface elevation exceedance tables for the 1978-2003 simulation period. 


\subsection{Conclusions}

The only ESP plant operational activity that would result in a detectable hydrological alteration of the environment is the discharge of waste heat from Unit 3. The additional withdrawal requirements from the new Unit 3 will result in shorter times for the water to travel from the discharge back to the intake than with Units 1 and 2 alone. Similarly, a decrease of lake volume due to additional induced evaporation from Unit 3 would also reduce the travel time between the discharge and the intake.

During normal operation at full power, based on the PPE, the primary cooling system for each unit is required to reject 9.7 E+09 BTU/hr to the environment. Unit 3 will reject this heat load via a once through cooling system. This design is the same as for NAPS Units 1 and 2 in that Unit 3 will withdraw water from Lake Anna adjacent to the location of the existing intakes and discharge the heated effluent to the discharge canal. The PPE also states that the flow rate through the condenser will not exceed 71,900 L/s (1,140,000 gpm). The once-through portion of the cooling system would return approximately the same amount of water to the discharge canal and the WHTF. The elevated temperature of the discharge would result in forced (induced) evaporative water losses, which are in addition to the natural (ambient) evaporative water losses from the lake. LakeWBT bounding used the applicant's bounding PPE estimates of forced evaporation for ESP Unit 3; 11,700 gpm for a once-through system and 19,500 gpm for a wet cooling tower design.

The existing NAPS units are the largest users of water in the region, and the addition of a third unit would add to this use. Most of the NAPS water drawn from Lake Anna for condenser cooling is non-consumptive as it is entirely returned to the lake. Although there is little consumptive use of water between the intake and discharge, the elevated temperature of the discharged water results in additional forced evaporative losses from the remainder of Lake Anna, and a third unit's once-through cooling system would add to this loss. While the increased circulation of water within Lake Anna resulting from the increased discharge from the Unit 3 will be detectable, it is only an impact inasmuch as it results in a change in the quantity and distribution of heat in the lake.

The impacts on water use are related to the water budget. Discharge of additional condenser cooling heat from Unit 3 to the lake would increase heat in the lake and increase evaporation. This additional volume of discharged cooling water would also change the hydrodynamic circulation of Lake Anna. The increased evaporation from Lake Anna from a third unit's once-through cooling system would increase the duration that releases from North Anna Dam are at or below 40 cfs (i.e. WSE below elevation 250 ft) by 11\% (6498 versus 5874 days between 1978-2003) as compared to only Units 1 \& 2 operating. However, the period of time the dam would be releasing 20 cfs (i.e. WSE below elevation $248 \mathrm{ft}$ ) would increase 121\% (1065 versus 481 days between 19782003). 
Lake temperature estimates used in the LakeWBT estimation of forced evaporation caused by the existing units were obtained from the applicant's calibrated and validated MIT model results. The staff used conservative temperature values from the MIT model as input into the staff's estimation of evaporative loss. By selecting upstream temperatures, conservatism was enforced. The temperature at the end of the discharge canal was used to represent the main portion of the WHTF. The temperature at Burrus Point was used to represent the main body of the lake. The arms of the main body were assumed to be at the equilibrium temperature.

The water budget modeling analysis assumed both the existing NAPS units and the oncethrough Unit 3 operated continuously at a 100\% load factor except when the lake WSE dropped below the operating threshold, at which point the impacted units ceased to operate. Four scenarios, including Unit 3 using an alternate cooling system (wet cooling towers), were selected to estimate the minimum water surface elevations: no units operating; Units 1 and 2 operating; Units 1 and 2 and the proposed Unit 3 (once-through system); and Units 1 and 2 and the proposed Unit 3 (wet tower cooling). The last scenario represents a water use upper bound. Modeled water surface elevations during the critical period between June 2000 through April 2003 produced the following minimum water surface elevations during the second week of October 2002:

No units operating: $247.8 \mathrm{ft}$

Units 1 and 2 (existing/observed conditions): $245.1 \mathrm{ft}$

Units 1 and 2 plus Unit 3 using once through cooling: $243.5 \mathrm{ft}$ Units 1 and 2 plus Unit 3 using wet cooling tower cooling: $\quad 242.5 \mathrm{ft}$

These values are similar to results provided in the application in which Dominion (2004) estimated that during the same critical period the water surface elevation would drop an additional $2 \mathrm{ft}$, from below $246 \mathrm{ft}$ to below $244 \mathrm{ft}$, with the addition of Unit 3 using a wet cooling tower design. 


\section{References}

Bras, R.L. (1990). Hydrology: An Introduction to Hydrologic Science, Addison Wesley Publishing, Reading, Massachusetts.

Brutsaert, W. (1991). Evaporation into the Atmosphere: Theory, History, and Applications, Kluwer Academic Publishers, Boston, Massachusetts.

Dominion Nuclear North Anna, LLC (Dominion). 2004. North Anna Early Site Permit Application . Revision 3, Glen Allen, Virginia.

EarthInfo Inc. (2003a). National Climatic Data Center Surface Airways TD-3280, East:2, CD-ROM Database, Boulder, Colo.

Edinger, J.E. D.K. Brady, and J.C. Geyer (1974) "Heat Exchange and Transport in the Environment”, Electric Power Research Institute, Cooling Water Discharge Research Project (RP-49), Palo Alto, CA, November.

NCDC (2004). TD-3200, Summary of the Day, Richmond International Airport and Richmond Byrd Field, WBAN ID 13740, Purchased Online via User Selection, National Climatic Data Center (NCDC), URL: http://nndc.noaa.gov/onlinestore.html, August 3.

Marciano, T.T., and G.E. Harbeck, Jr (1954). “Mass Transfer Studies”, in Water Loss Investigations, Lake Hefner Studies, Technical Report, U.S. Geological Survey, Professional Paper 269.

McCutcheon, S.C. (1989) Water Quality Modeling, Volume 1 Transport and Surface Exchange in Rivers, CRC Press, Boca Raton, Florida.

TVA (1972). "Heat and Mass Transfer between a Water Surface and the Atmosphere”, Water Resources Research, Laboratory Report No 14 prepared for the Tennessee Valley Authority, Division of Water Control Planning, Engineering Laboratory, Report No. 06803, Norris, Tennessee, April.

Van der Leeden, F., F.L. Troise, and D.K. Todd. 1990. The Water Encyclopedia. Lewis Publishers, Chelsea, Michigan. 


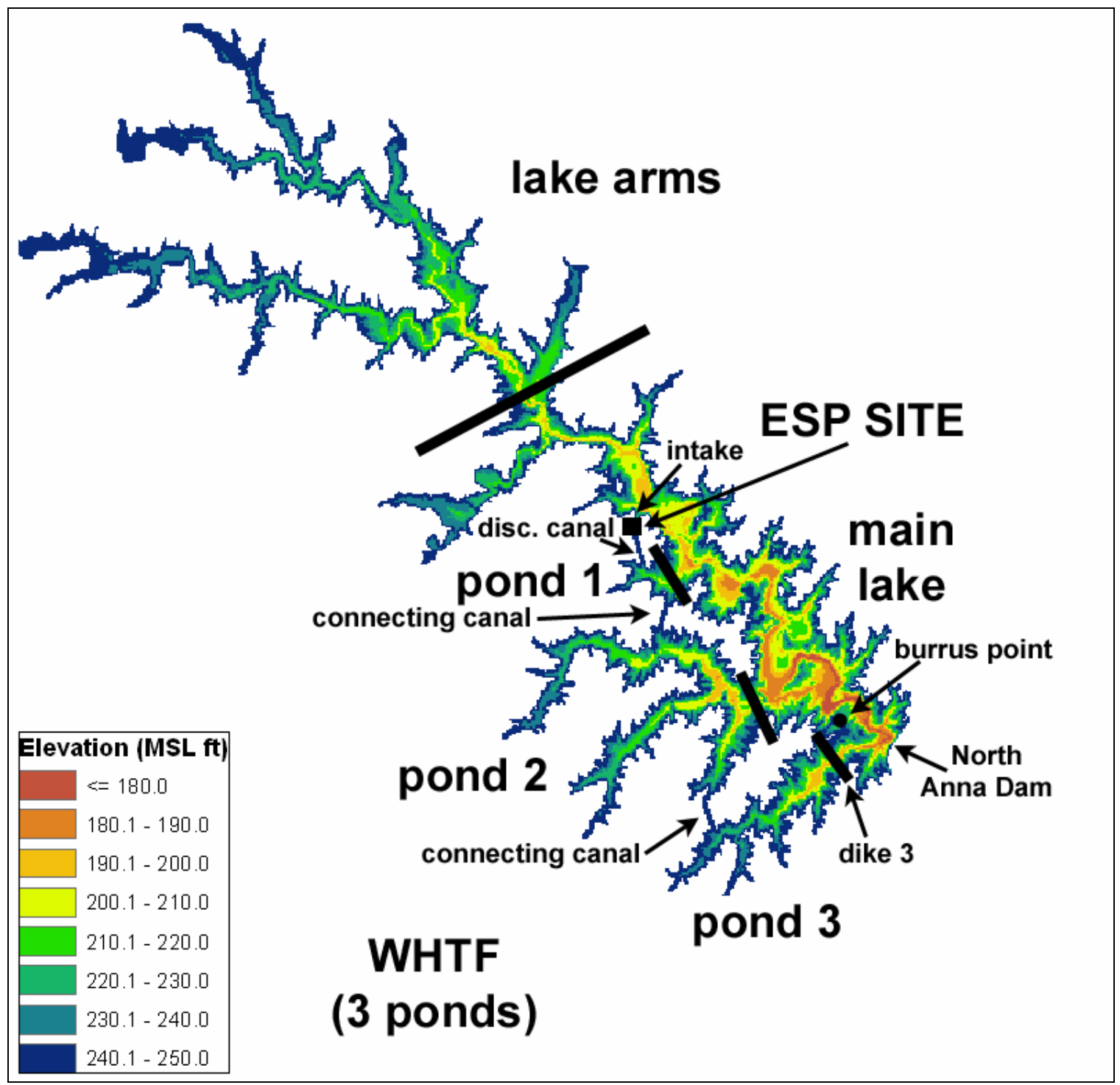

Figure 1 Main features of Lake Anna. 


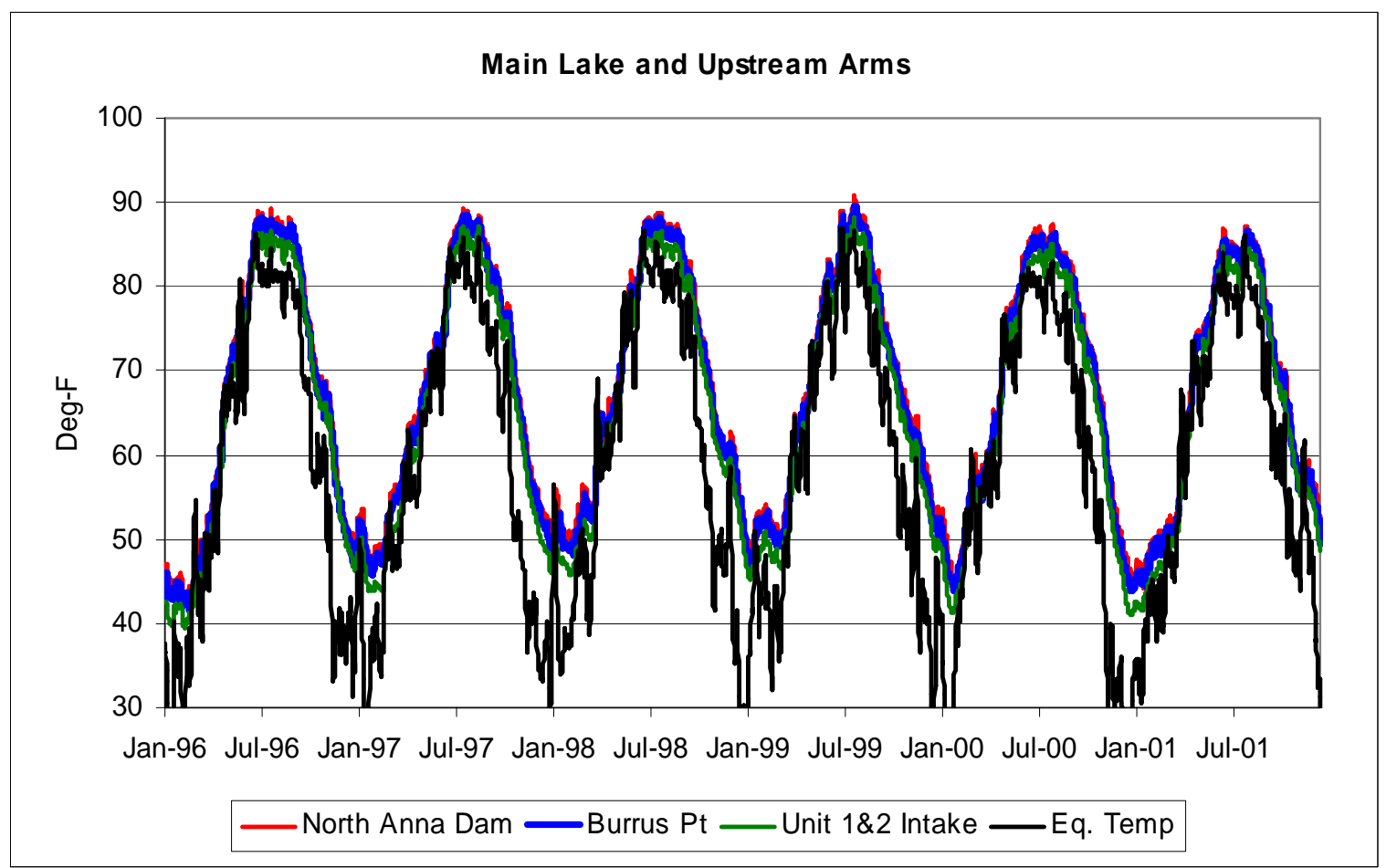

Figure 2 Main lake and main lake arm temperatures observed and computed by the MIT model. 


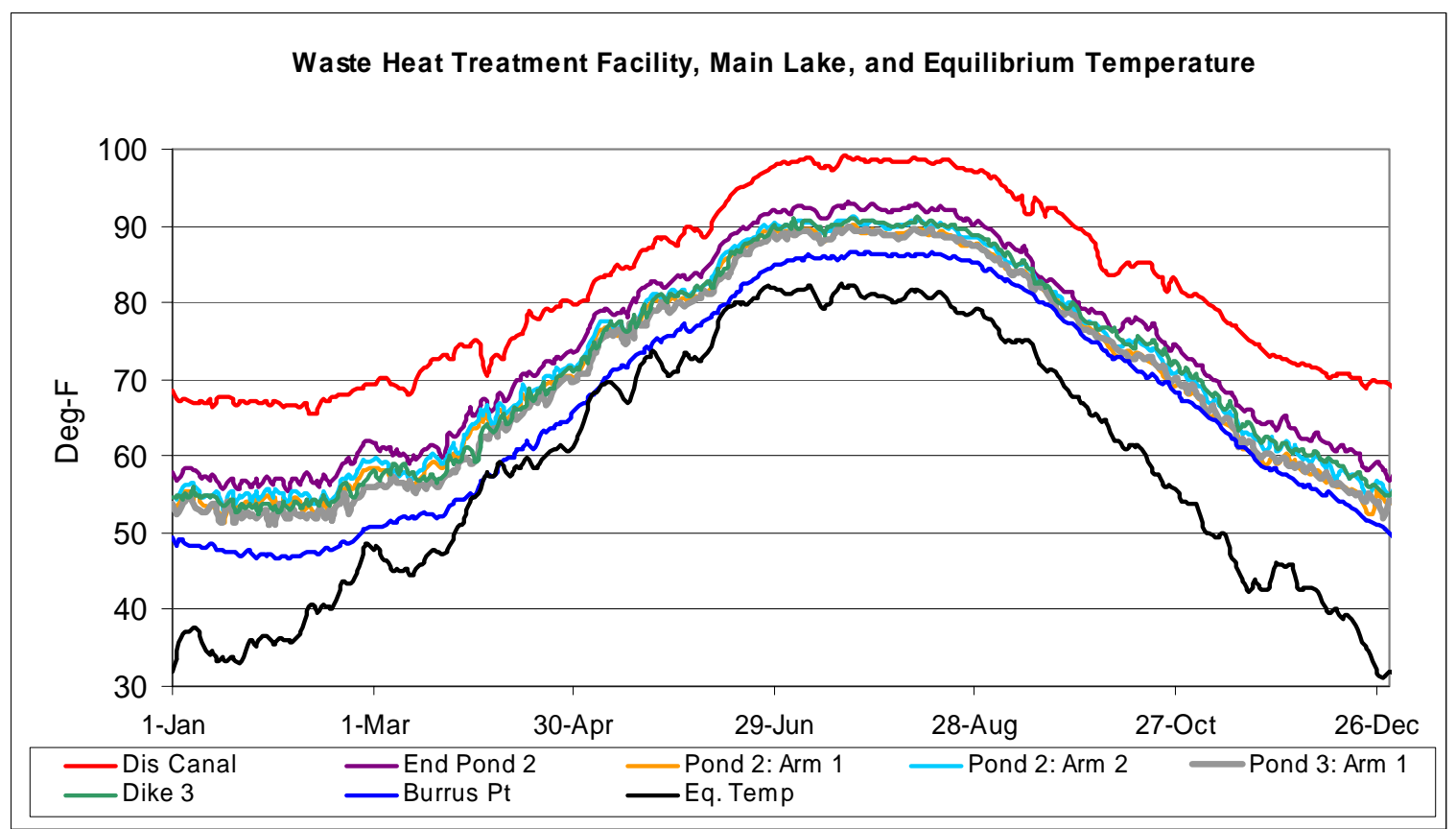

Figure 3 Date-averaged water temperatures for the WHTF, main lake, and equilibrium for the period 1996-2001. 


\section{Monthly Precipitaiton at Richmond Airport}

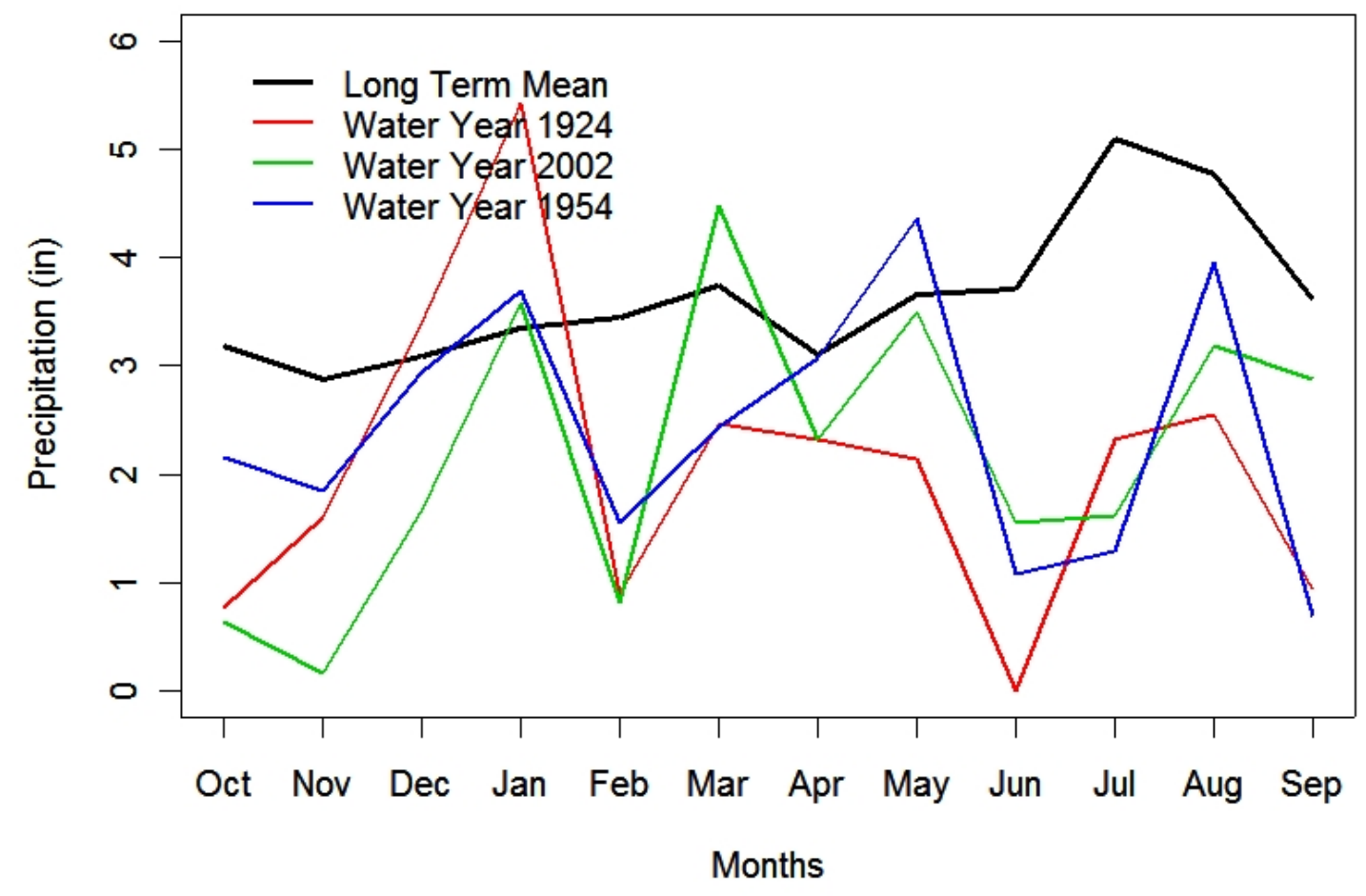

Figure 4 Long-term mean monthly precipitation and monthly precipitation during three driest water years in the record. 


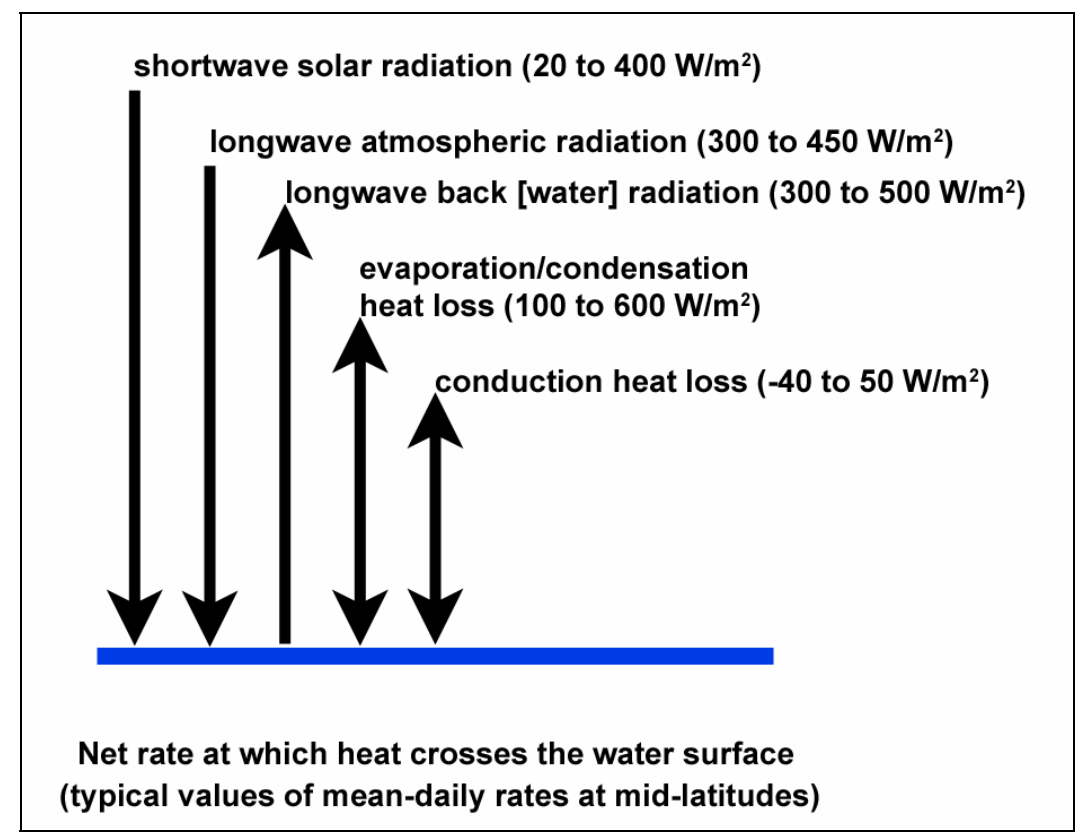

Figure 5 Five principle components used to compute heat flux at the water surface. Values shown are mean-daily values (Edinger, 1974) 


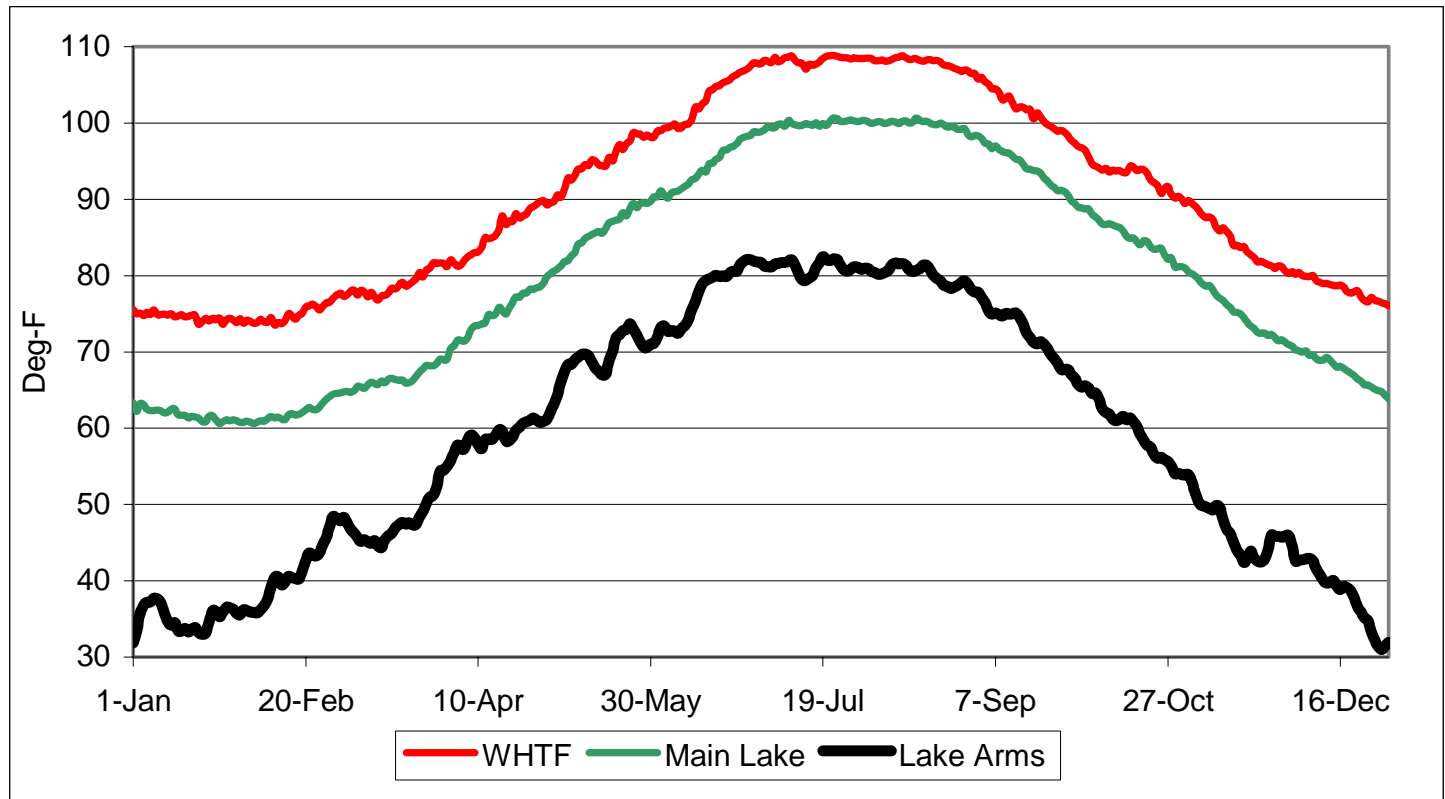

Figure 6 Water temperatures which provided the basis of the direct scaled temperature assessment. 


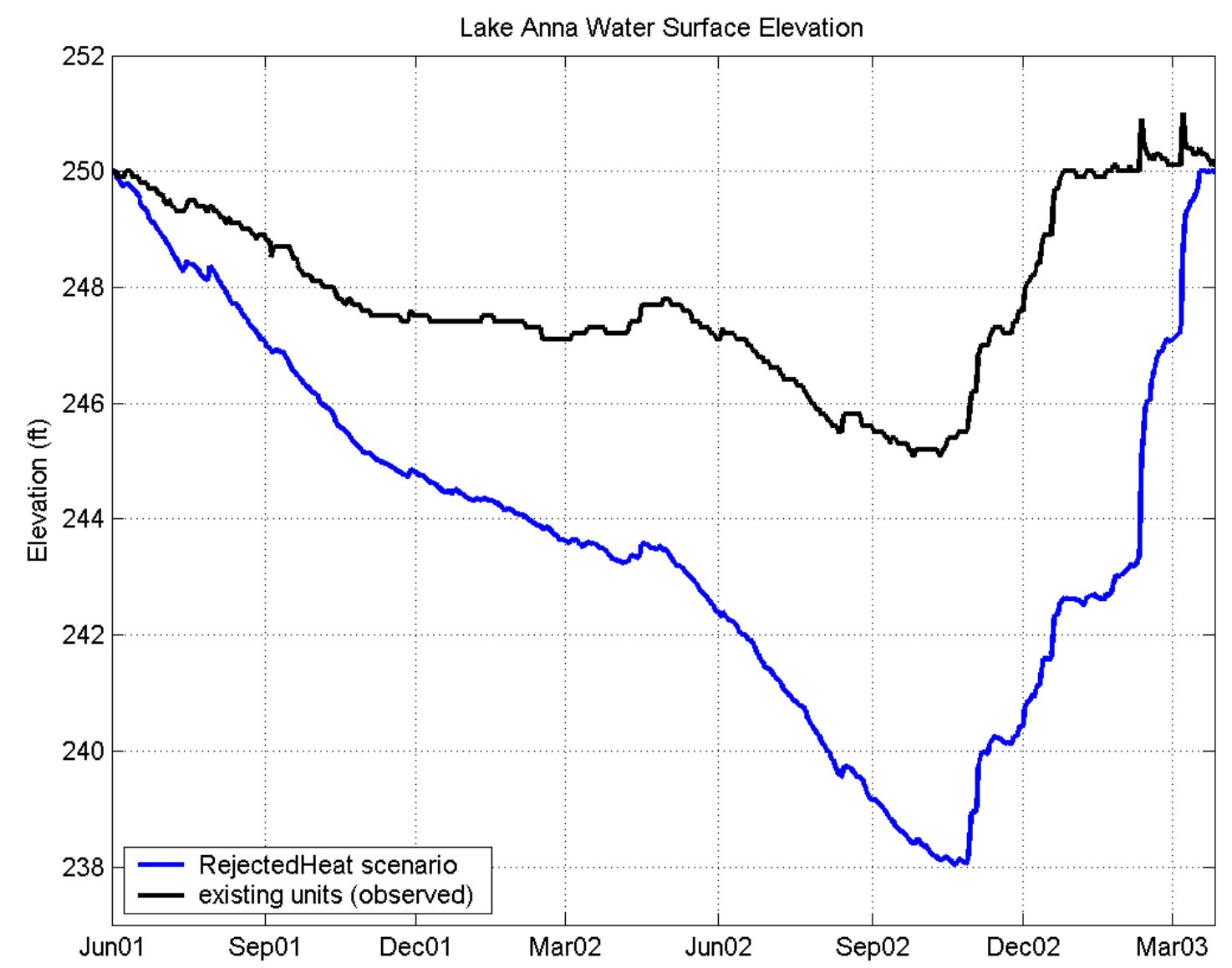

Figure 7 Predicted and observed water surface elevations based on the direct scaled temperature approach. 


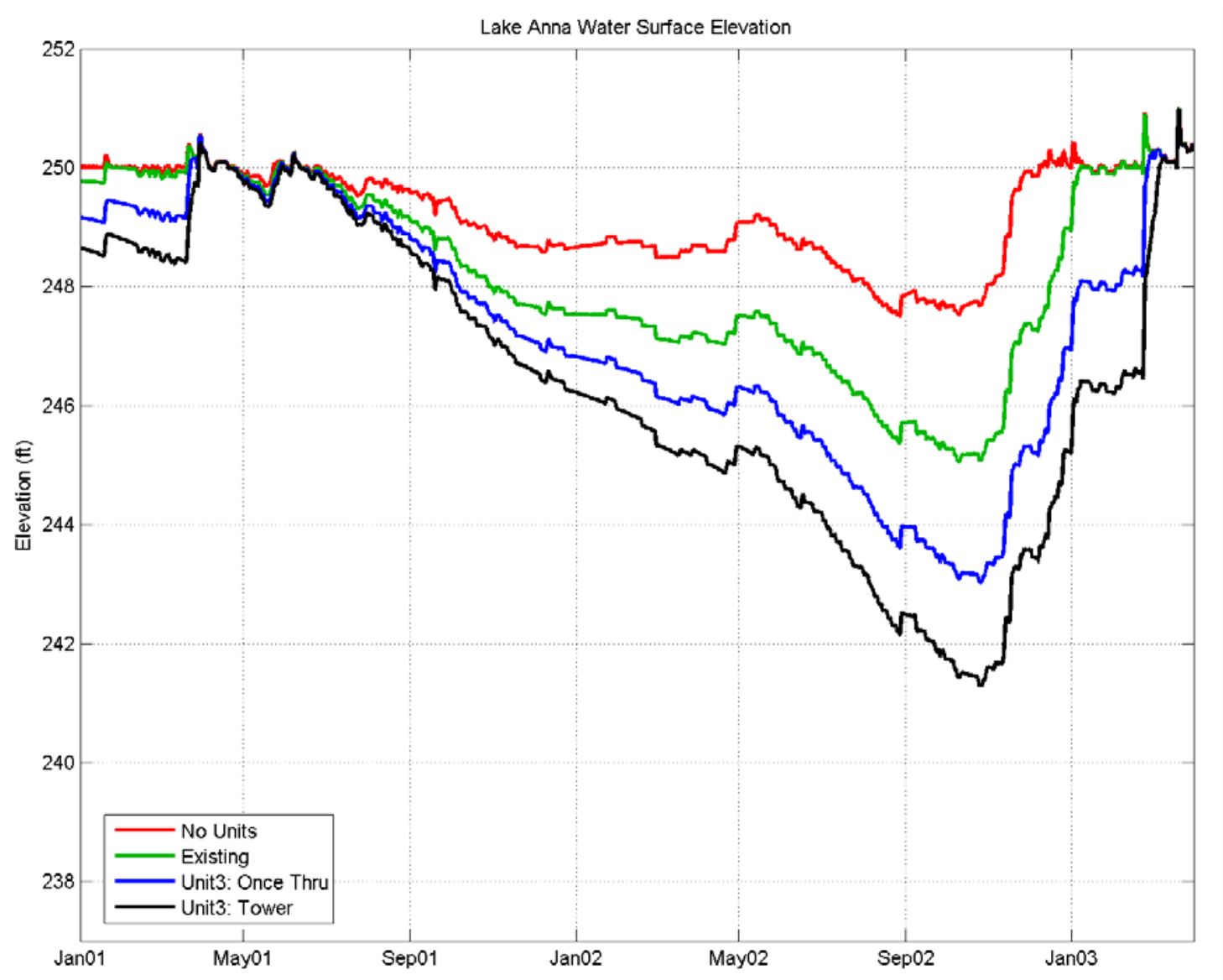

Figure 8 Water surface elevations predicted during the critical period using the constant temperature hot thermal pool approach 


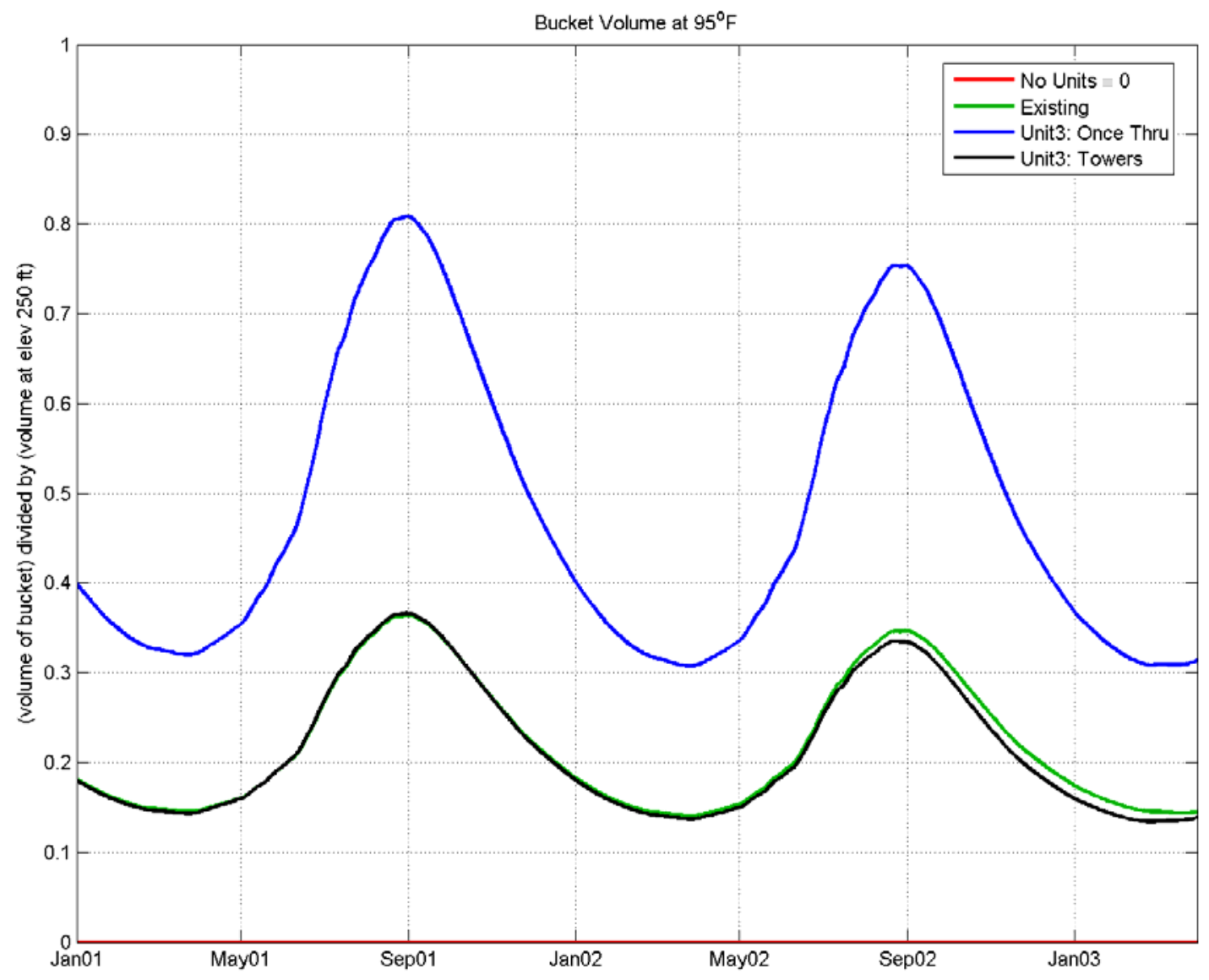

Figure 9 Relative fraction of lake volume as $95^{\circ} \mathrm{F}$ pool using the constant temperature hot thermal pool approach 

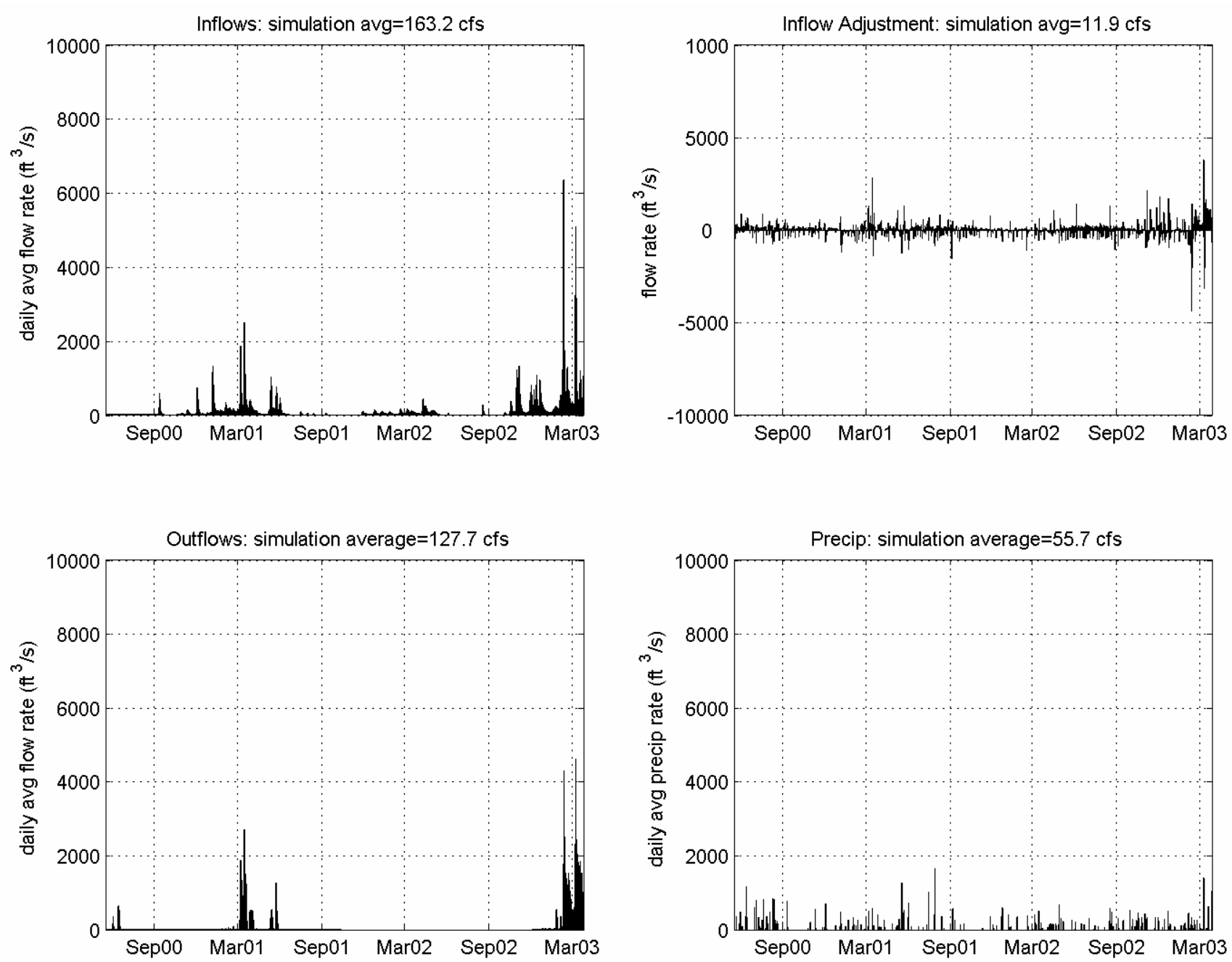

Figure 10 Inflows, outflows, precipitation and flow adjustments using Newton’s Method: Units 1 \& 2 scenario. 


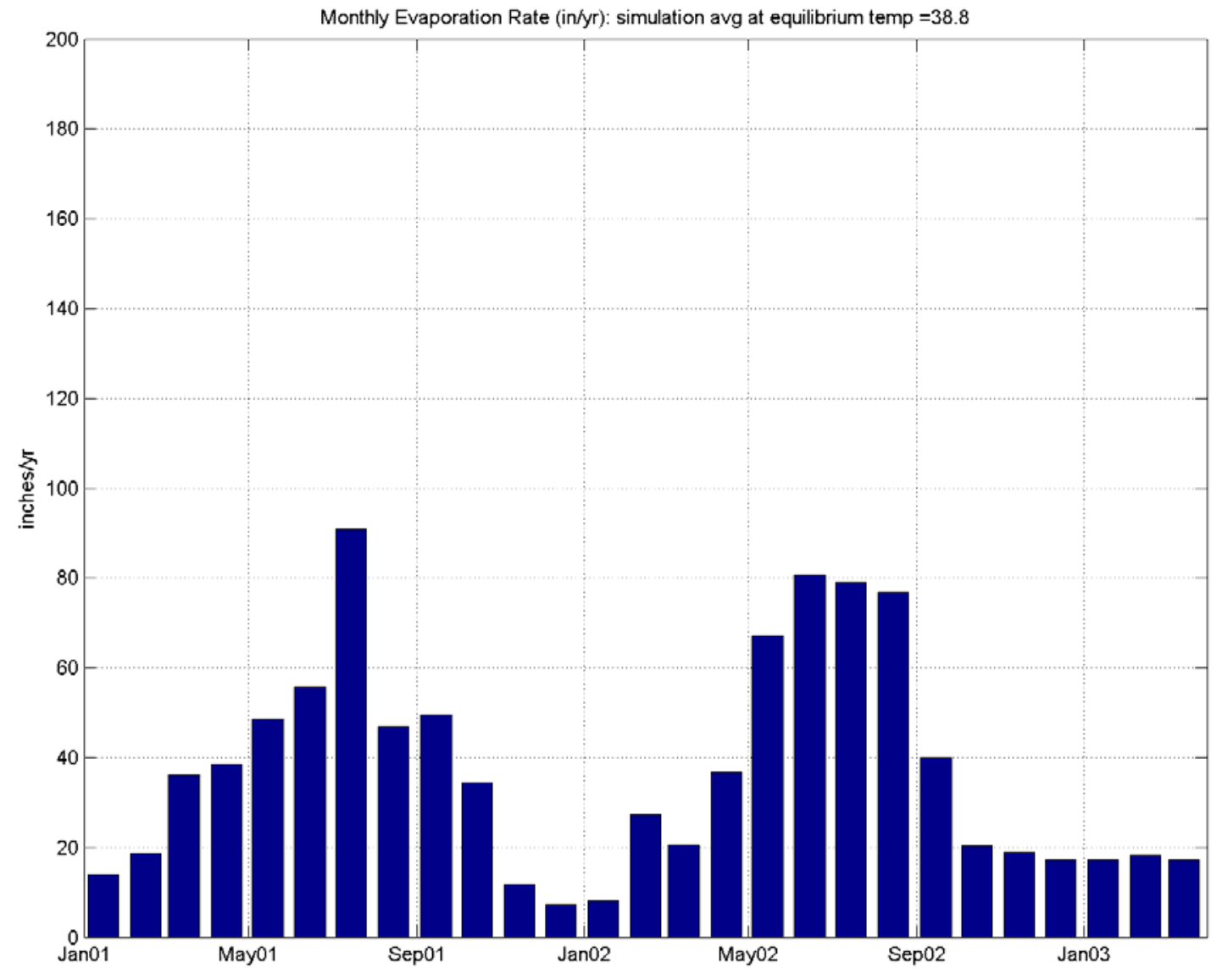

Figure 11 Natural (ambient) evaporation rate for Lake Anna during the critical period. 

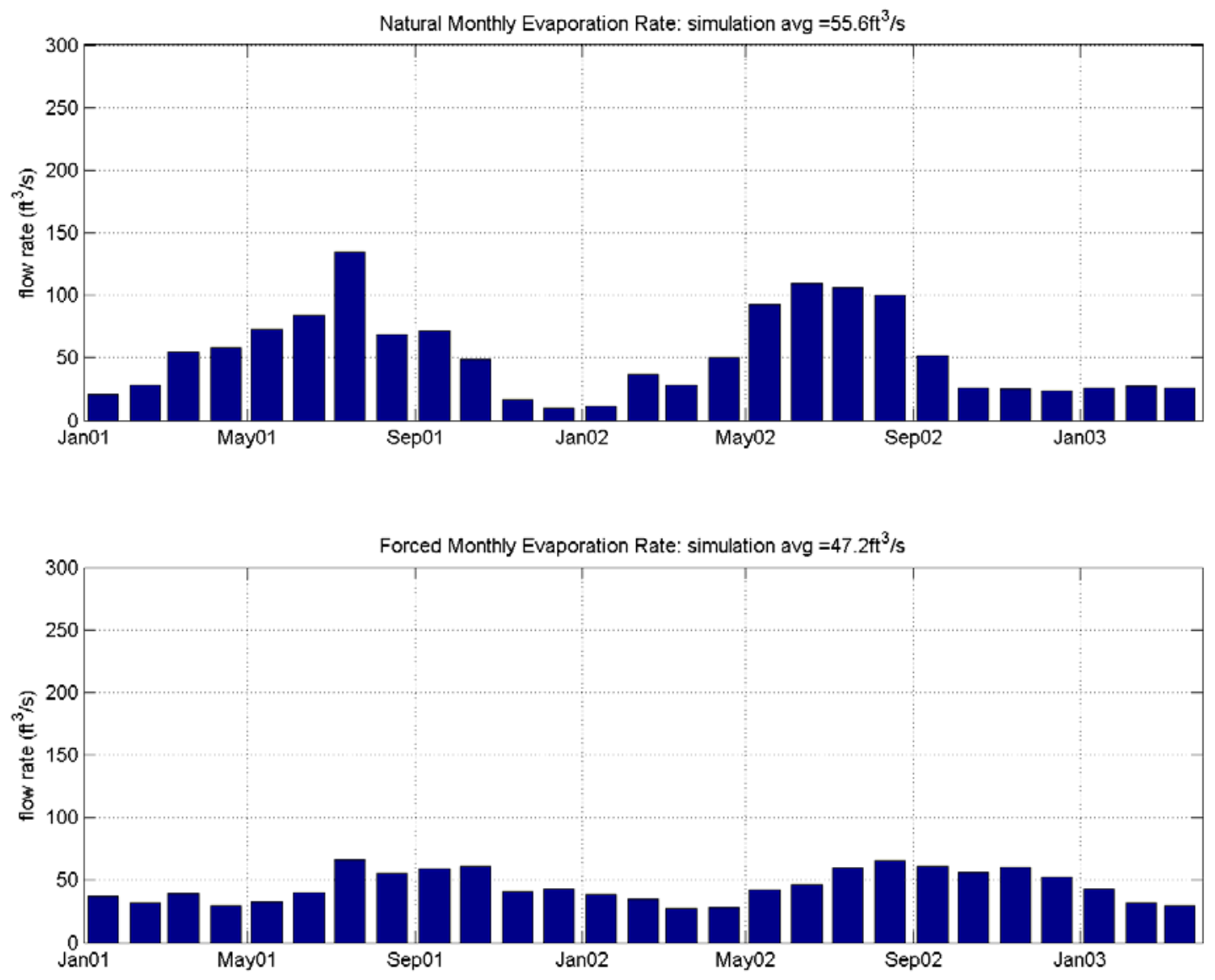

Figure 12 Natural and forced evaporation computed using Newton's Method: Units 1\&2 scenario. 


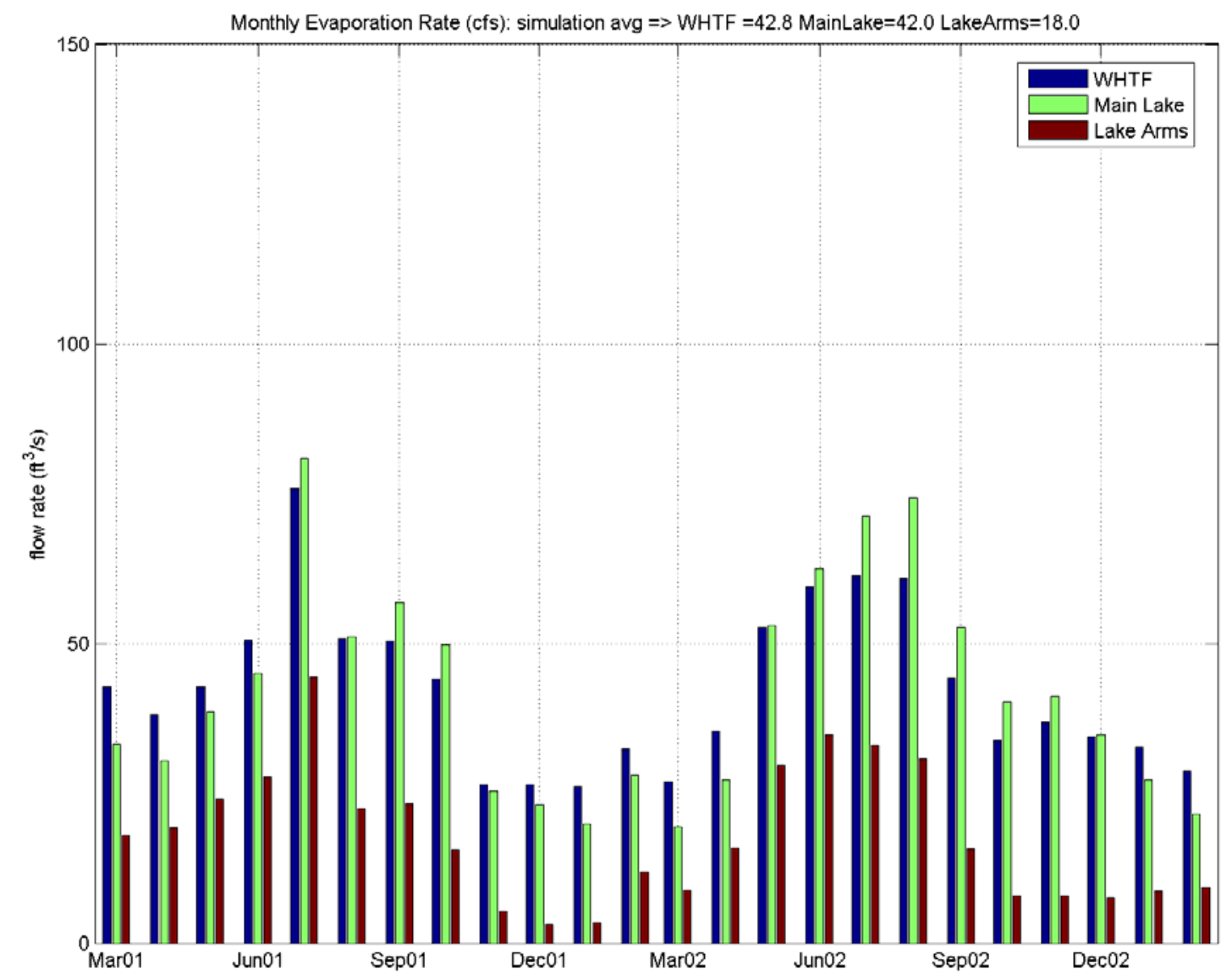

Figure 13 Monthly average evaporation rates in CFS and by main lake feature using Newton's Method: Units $1 \& 2$ scenario. Note that the relative surface areas of the features are: $\mathrm{WHTF}=24 \%$, main lake $=42 \%$, and lake arms $=33 \%$. 

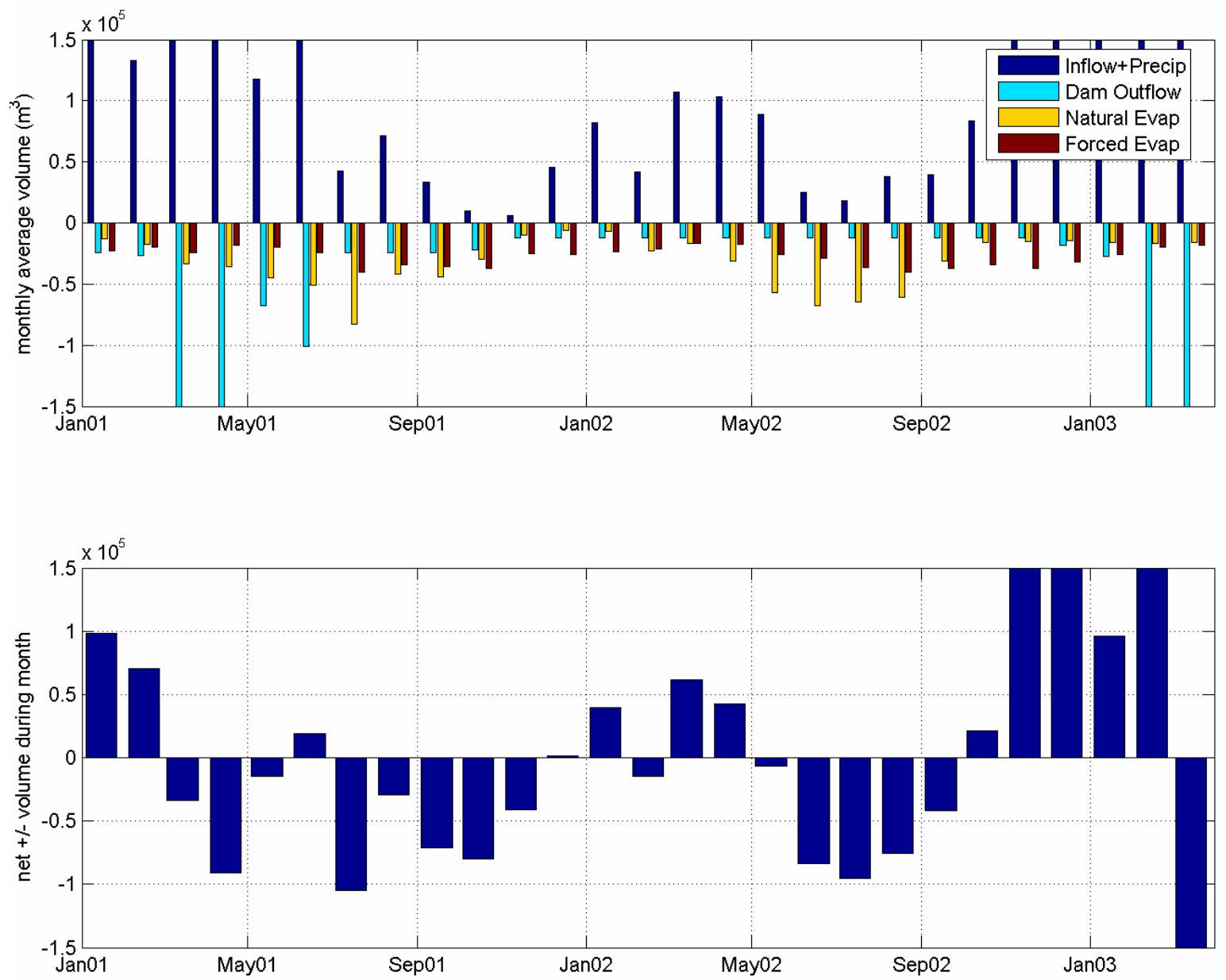

Figure 14 Volume fluxes for the critical period using Newton's Method: Units 1\&2 scenario. Upper graphic displays the magnitude of the individual terms in the water budget, while the bottom graphic displays the net sum. Positive values are into the lake while negative values are out of the lake. 


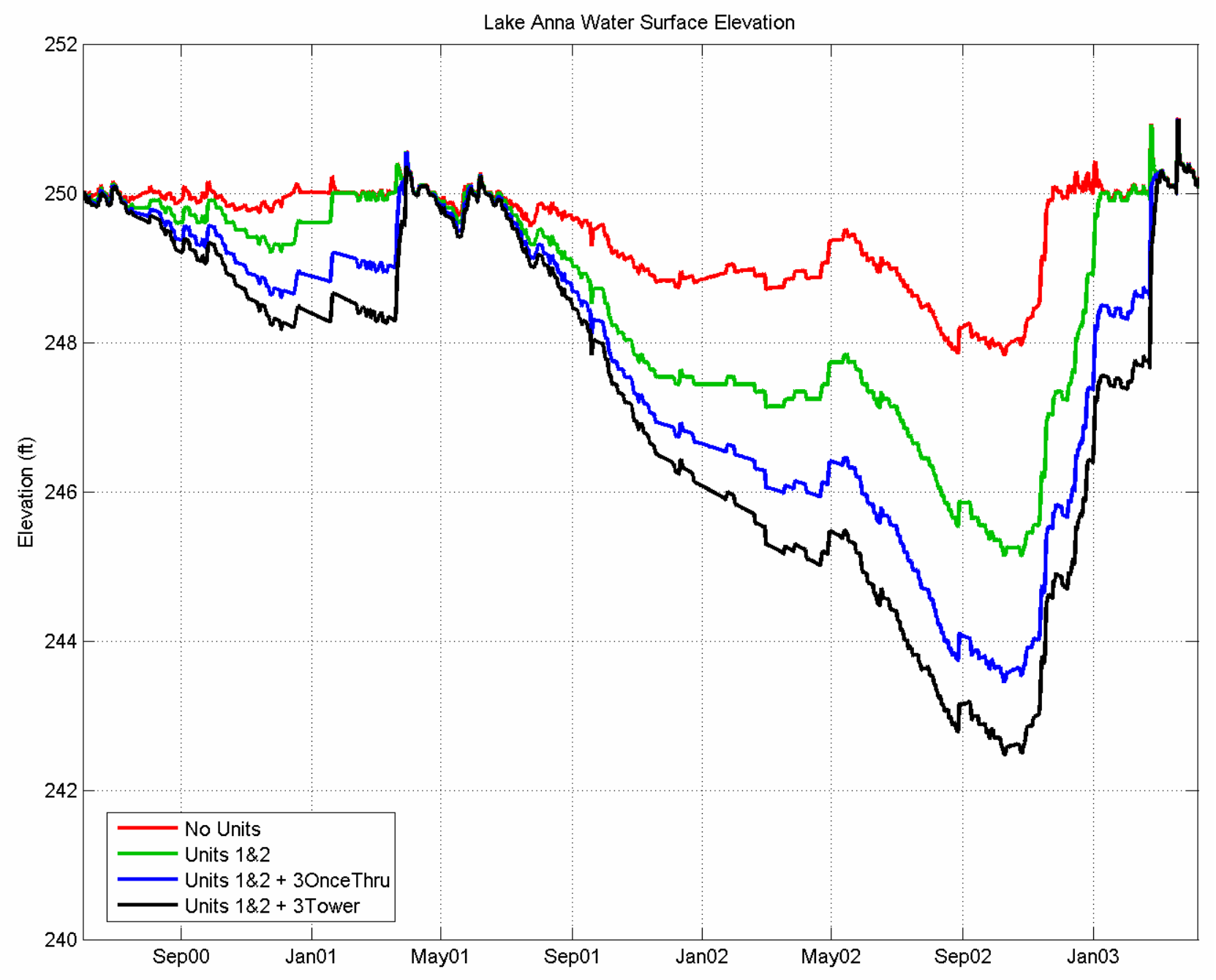

Figure 15 Composite WSE predictions using Newton’s Law of Cooling Method. 
Appendix A. Simulation Results for the Critical Period: June 2000 through April 2003. 


\section{No Units Operating Scenario}
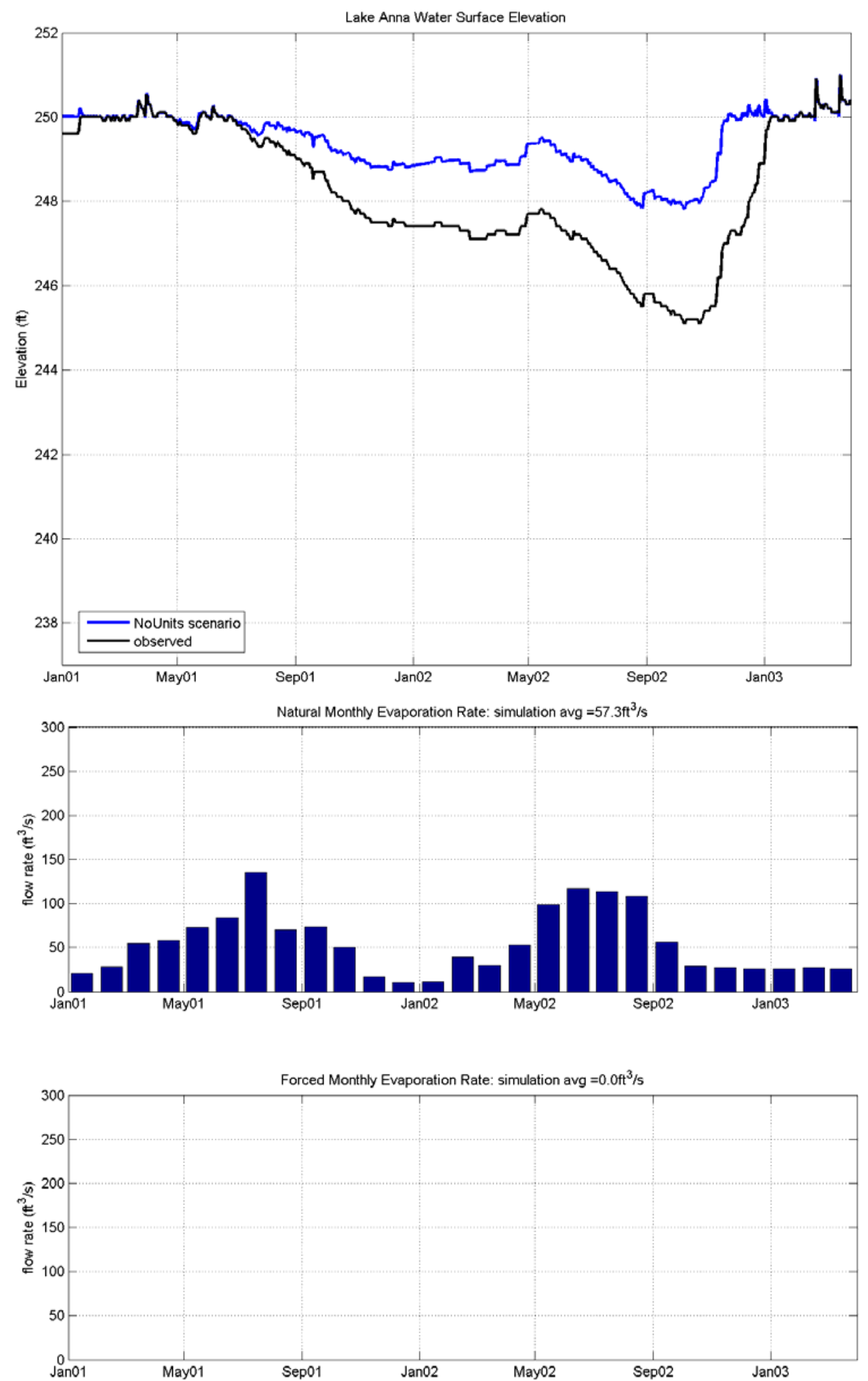


\section{Existing Units 1 \& 2 Operating Scenario}
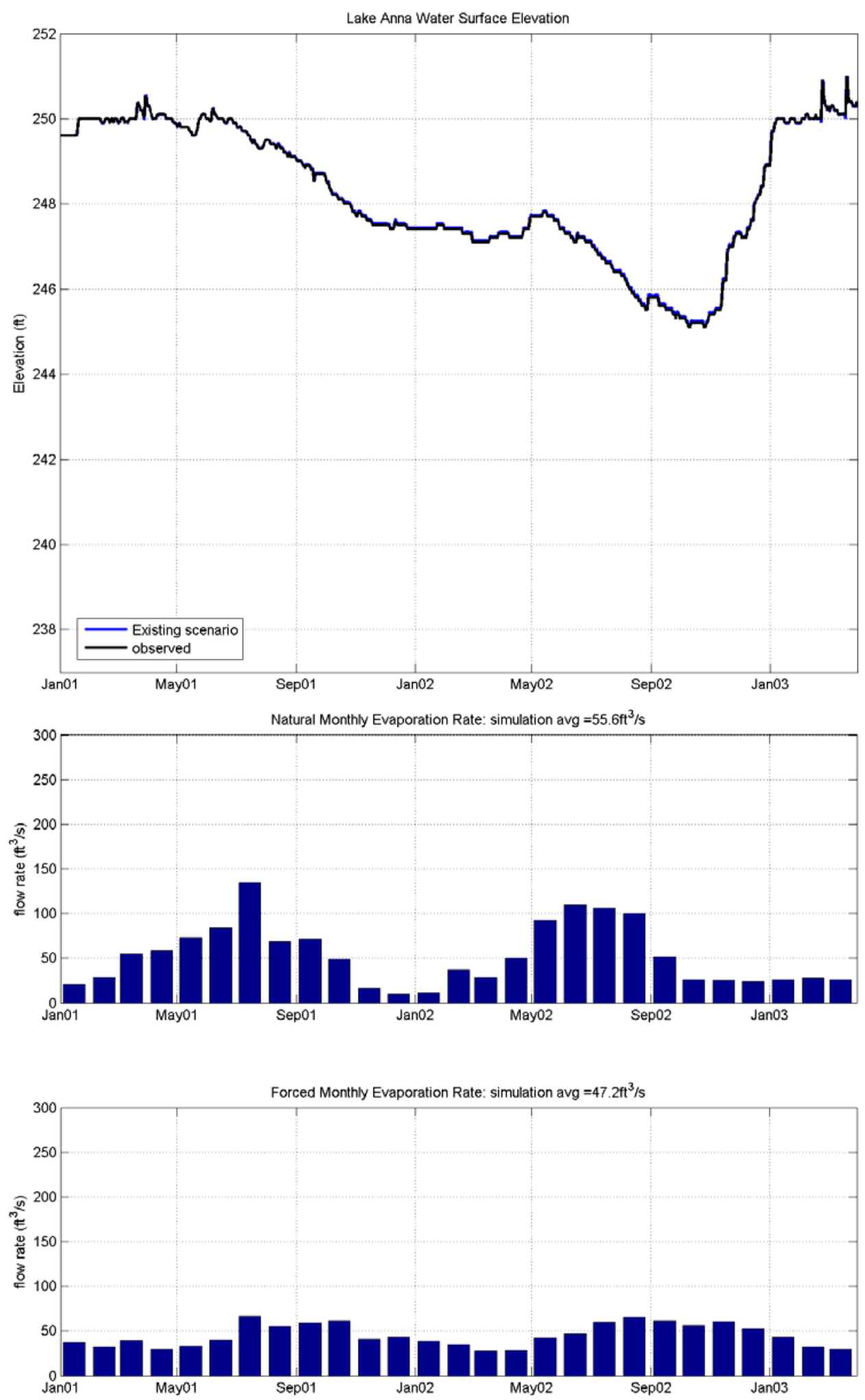


\section{Units 1 \& 2 plus Unit 3 with once-thru cooling}
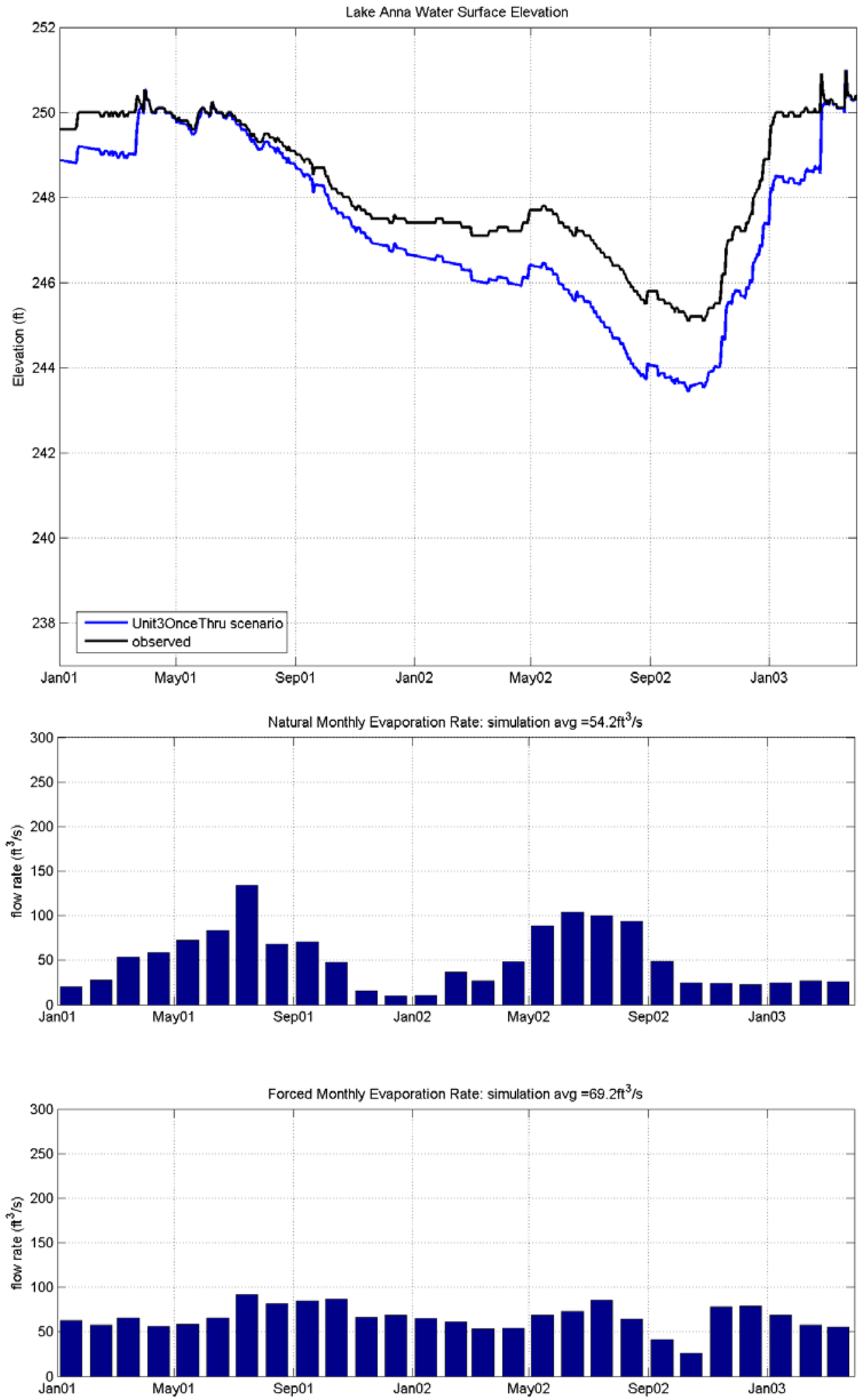


\section{Units 1 \& 2 plus Unit 3 with wet tower cooling}
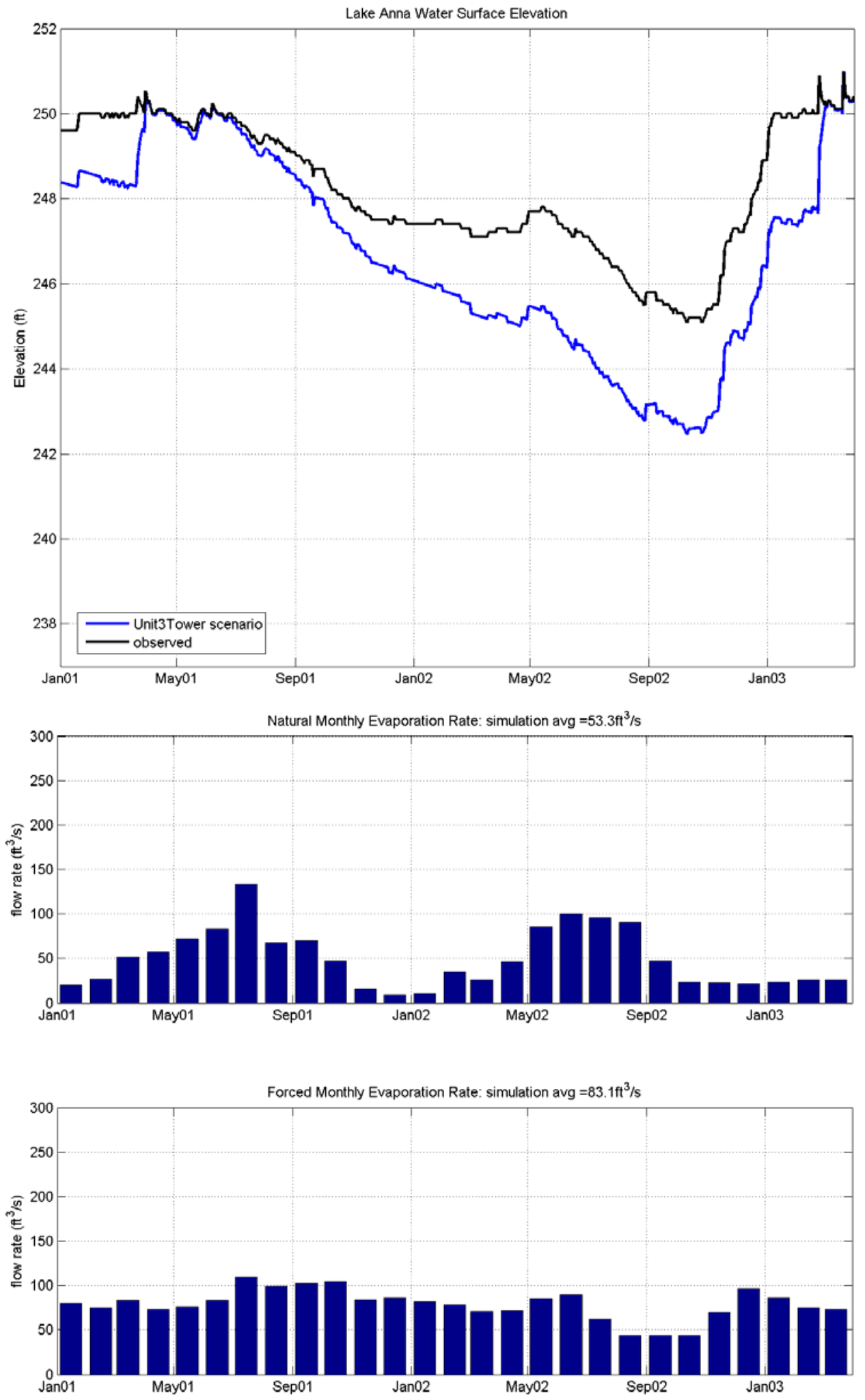
Appendix B. Simulation Results for the Period of Observed Field Data: October 1978 through April 2003. 


\section{Inflows and Outflows for Unit 1\&2 Scenario}
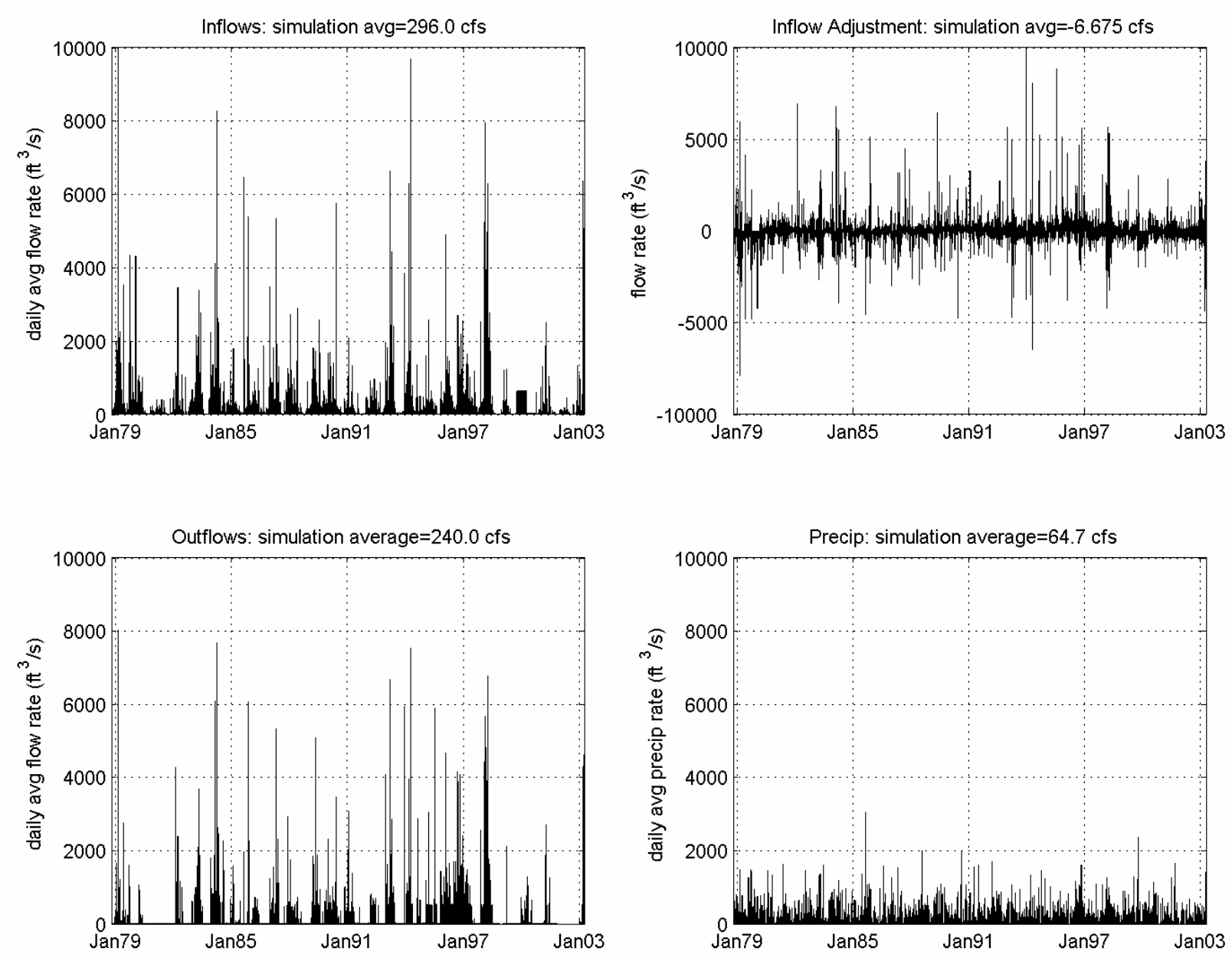


\section{Natural Evaporation Rate: same for all scenarios}

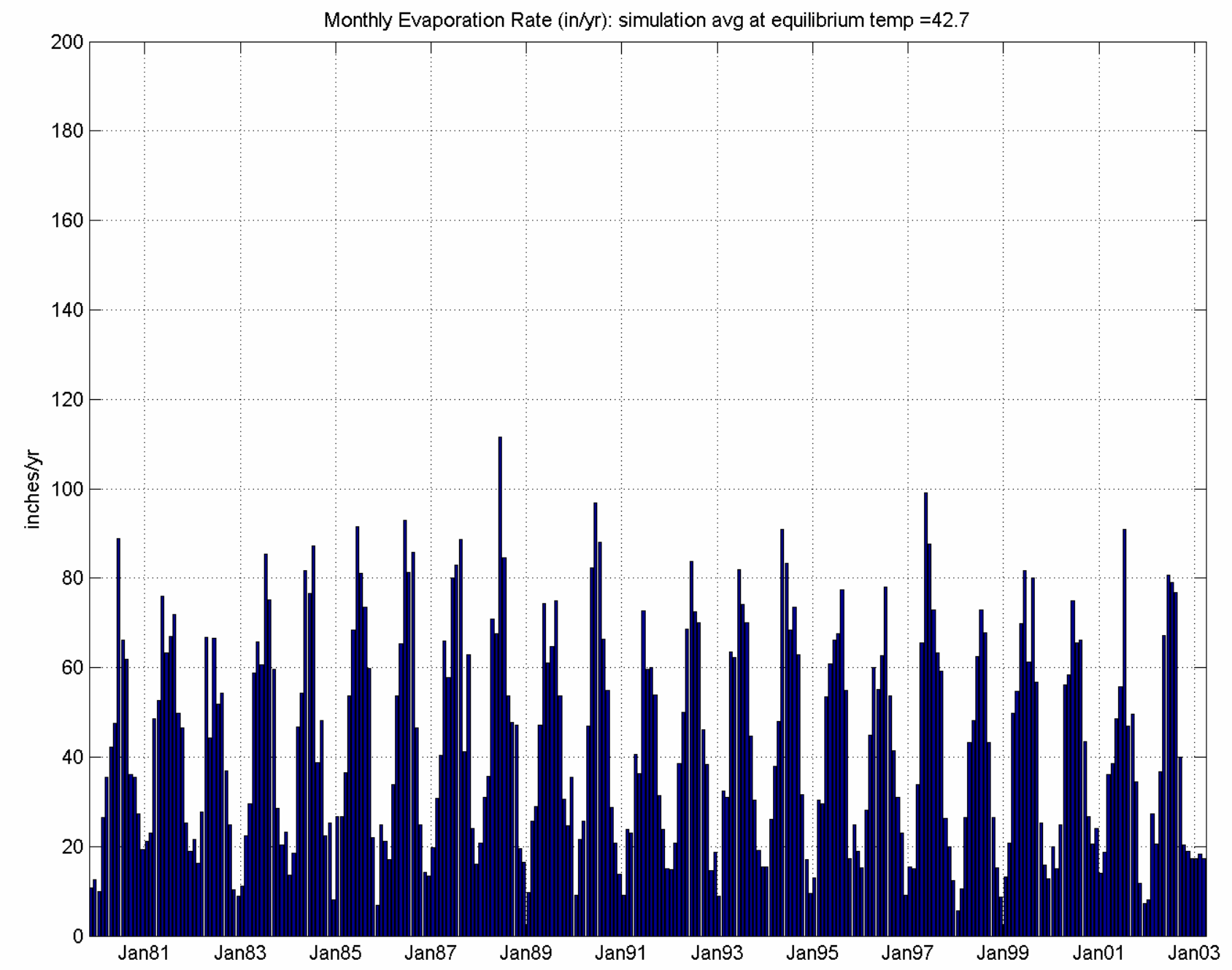




\section{No Units Operating Scenario}
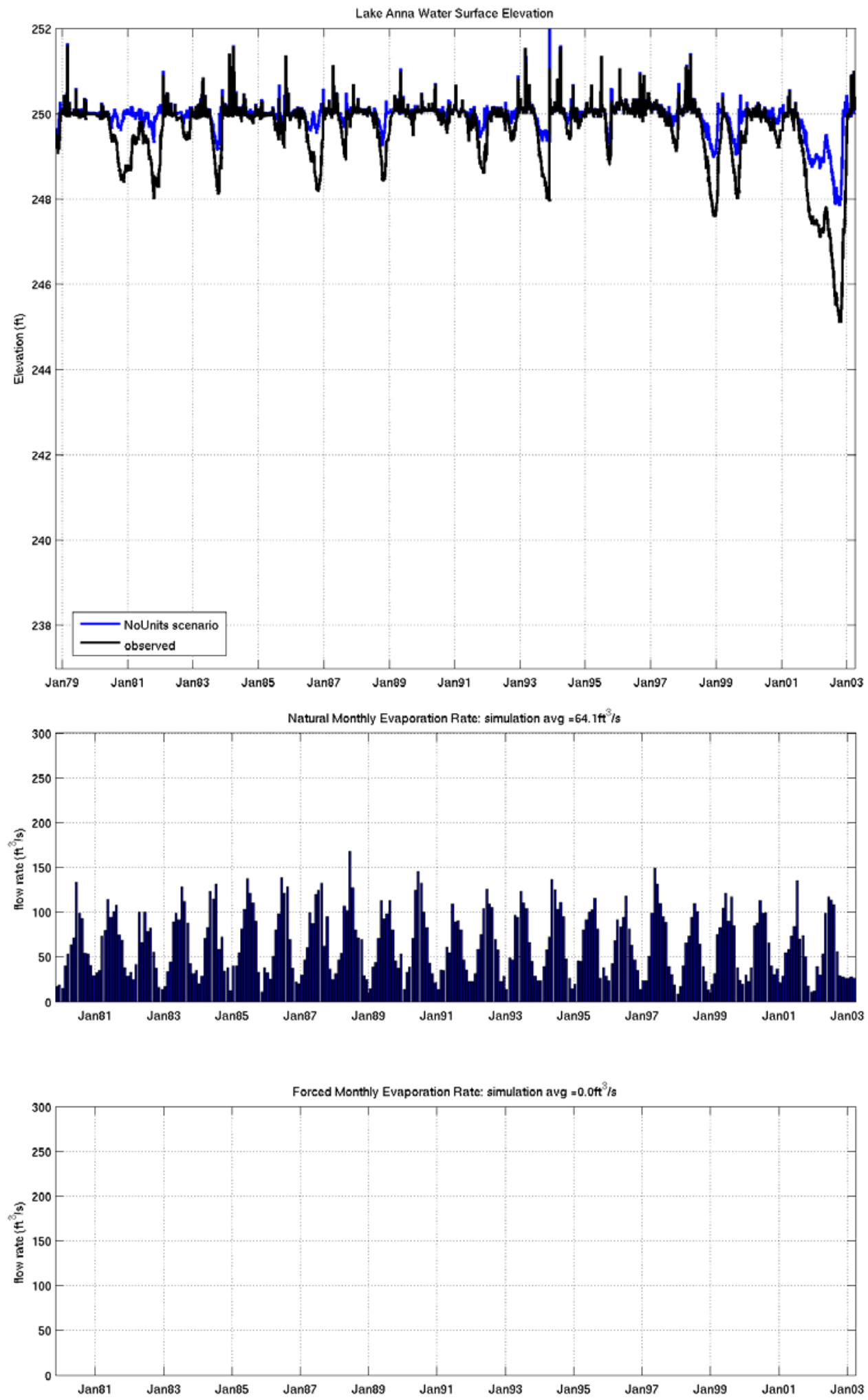


\section{Existing Units 1 \& 2 Operating Scenario}
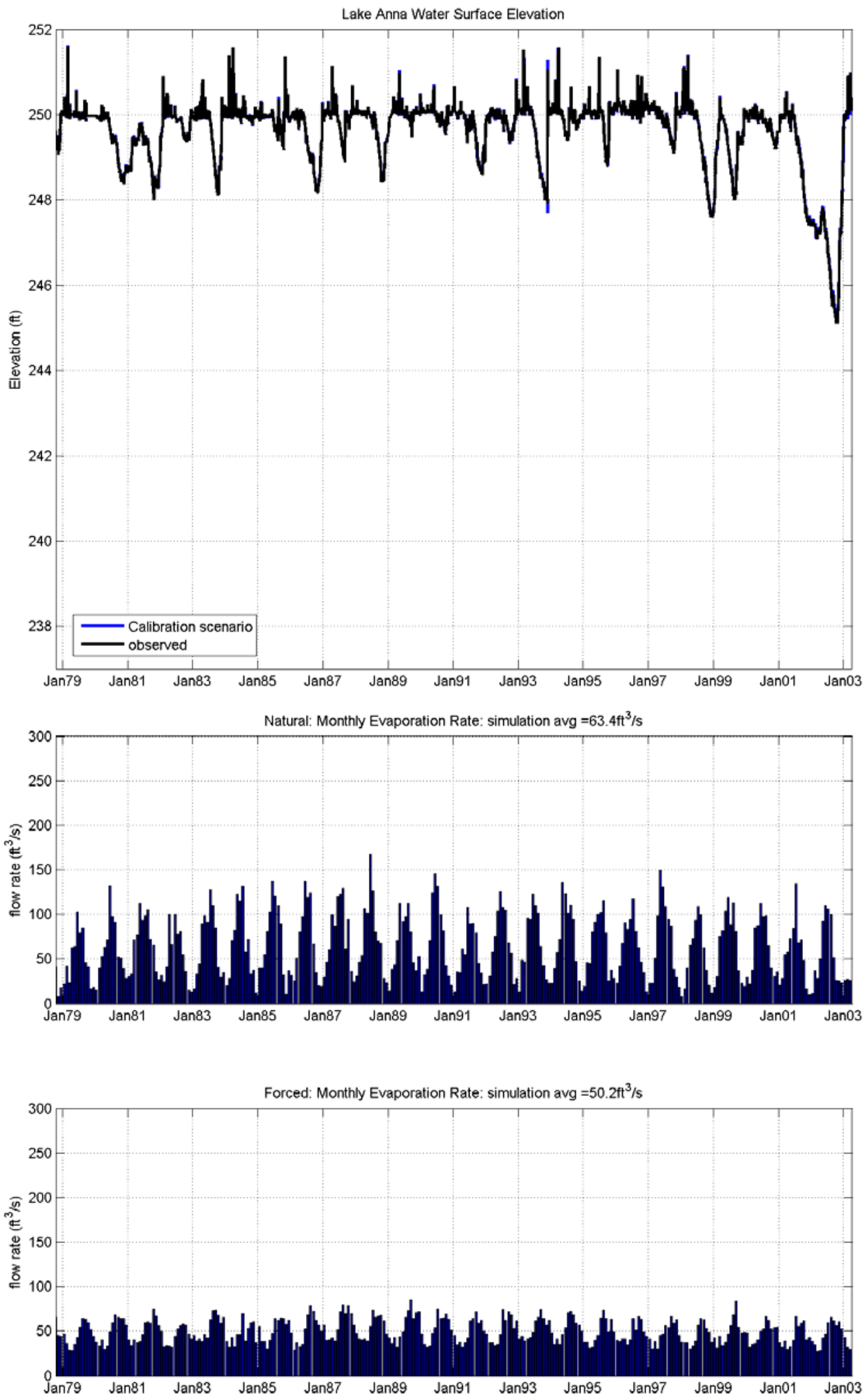


\section{Units 1 \& 2 plus Unit 3 with once-thru cooling}
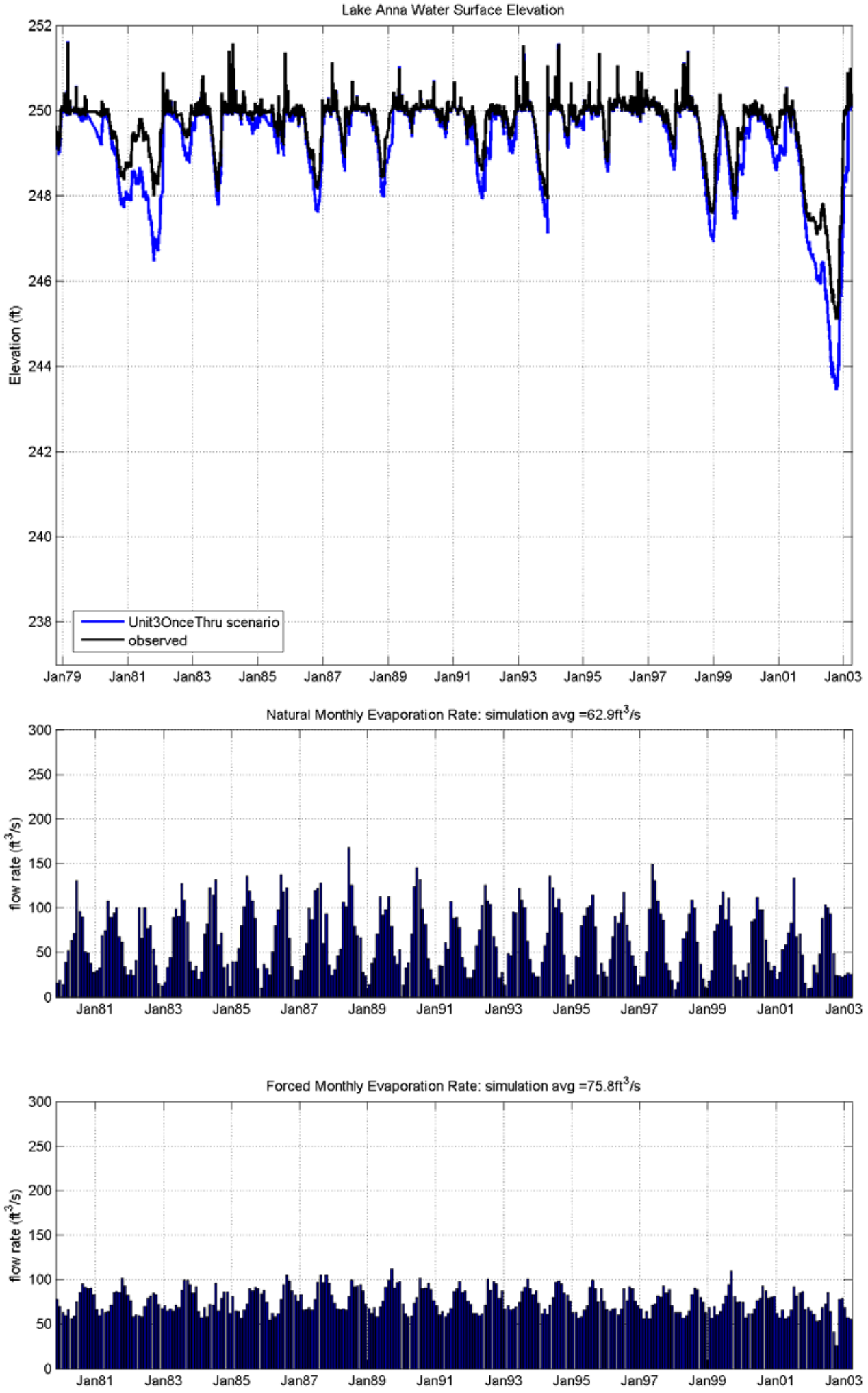


\section{Units 1 \& 2 plus Unit 3 with wet tower cooling}
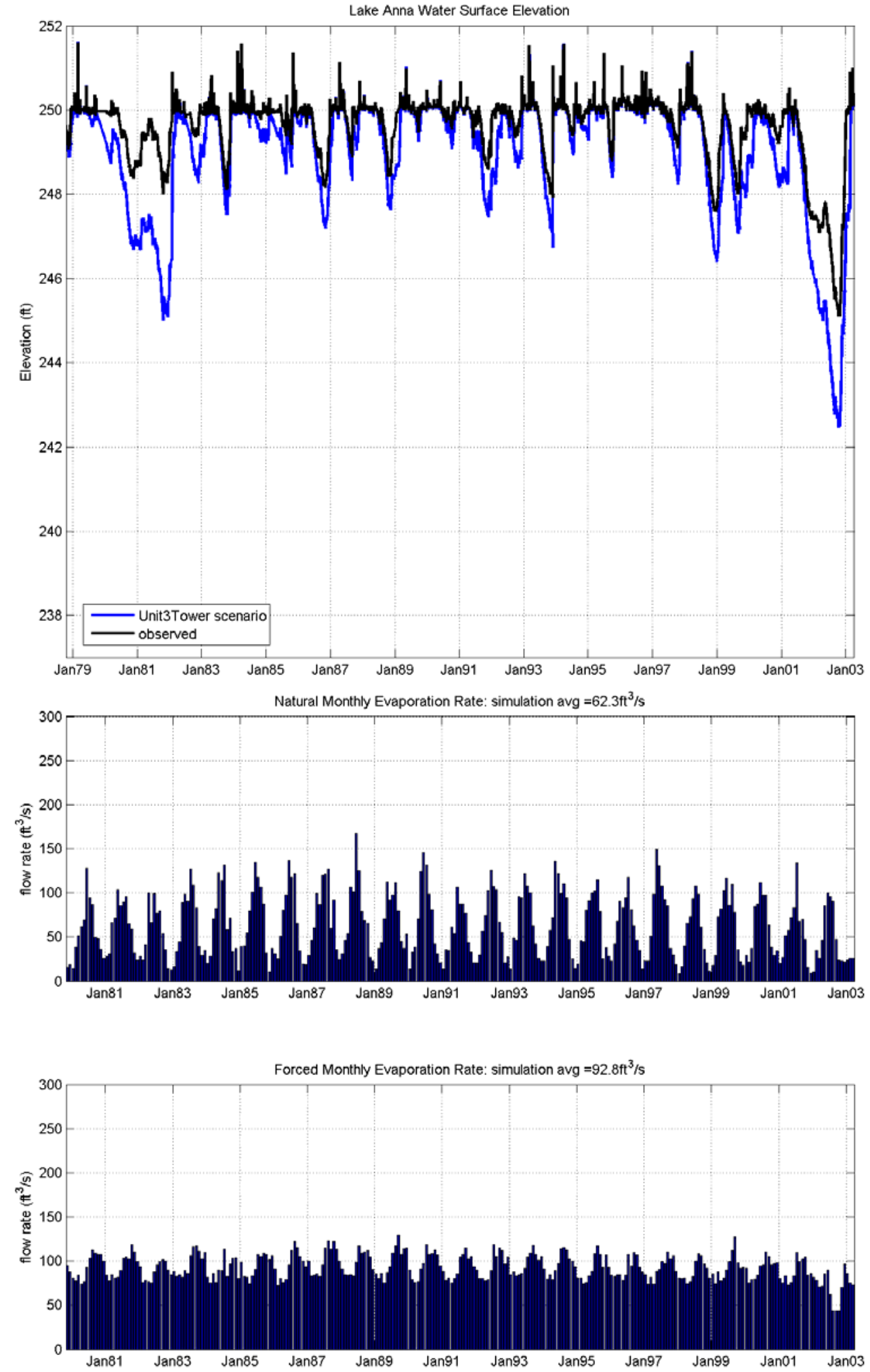